\title{
A review of indices for assessing visual comfort with a view to their use in optimization processes to support building integrated design
}

\author{
Salvatore Carlucci a, ${ }^{\text {a }}$, Francesco Causone ${ }^{\mathrm{b}}$, Francesco De Rosa ${ }^{\mathrm{b}}$ and Lorenzo Pagliano ${ }^{\mathrm{b}}$ \\ ${ }^{a}$ NTNU Norwegian University of Science and Technology, Department of Civil and Transport Engineering, Trondheim, Norway. \\ b end-use Efficiency Research Group, Dipartimento di Energia, Politecnico di Milano, Milano, Italy. \\ *Corresponding author. Tel.: +47 735 94634. E-mail address: salvatore.carlucci@ntnu.no (S. Carlucci).
}

\begin{abstract}
In the last decades, several studies aimed at assessing some specified aspects of visual comfort characterizing the relationship between the human needs and the light environment, such as an available amount of light, light uniformity, light quality in rendering colors, and predicting the risk of glare for space occupants. For each of them, a (still growing) number of indices and metrics have been proposed in literature and standards. In the present work, they are described, categorized according to common features, and finally discussed. As in the case of long-term thermal comfort indices, such visual comfort indices and their summation over a specified calculation period might be used for driving optimization processes to support a more conscious integrated design of buildings. To that purpose, the choice among the available visual comfort indices needs to be informed by an analysis of their features and implications. We present recommendations for use, and suggest areas where improvement is needed for their use in optimization processes to support buildings' design.
\end{abstract}

\section{Keywords}

Visual comfort, visual comfort assessment, visual discomfort indices, glare, daylight, lighting, objective functions.

\section{Acronyms}

\author{
ASE Association Suisse des Electriciens \\ BGI British Glare Index \\ BRS Building Research Station \\ CEN European Committee for Standardization \\ CCT Correlate Color Temperature \\ CGI CIE Glare Index \\ CIE Commission Internationale de l'Eclairage \\ CRC Color Rendering Capacity \\ CQS Color Quality Scale
}


DA Daylight Autonomy

$D A_{C O N}$ Continuous Daylight Autonomy

DF Daylight Factor

DGI Daylight Glare Index

DGP Daylight Glare Probability

DGPs Simplified DGP

eDGPs Enhanced Simplified DGP

FVC Frequency of Visual Comfort

IEA International Energy Agency

IES Illuminating Engineering Society

IESNA Illuminating Engineering Society of North America

IU Illuminance Uniformity

IVD Intensity of Visual Discomfort

LED Light Emitting Diode

LEED Leadership in Energy and Environmental Design

OLED Organic Light Emitting Diode

PGSV Predicted Glare Sensation Vote

sDA Spatial Daylight Autonomy

TC Technical Committee

UDI Useful Daylight Illuminance

UGR CIE Unified Glare Index

VPC Visual Comfort Probability

\section{Nomenclature}

$A$
$E$
$G$
$G($ Test $) ; G(D 65)$
$I$
$L$
$M$
$p$
$P$
$r$
$\tilde{H}$
$R_{a}$
$R_{f}$,
$t$
$U_{o}$
$w f$
$\omega$

Area

$\mathrm{m}^{2}$

Illuminance

lux

Glare

Gamut area

Luminous intensity

Luminance

Glare sensation index

Point belonging to the calculation grid

Position index

Distance between that light source and observer's eyes

cd

Relative influence

Color Rendering Index

Flattery Index

Time (hour)

Illuminance Uniformity

Weighting factor

Solid angle

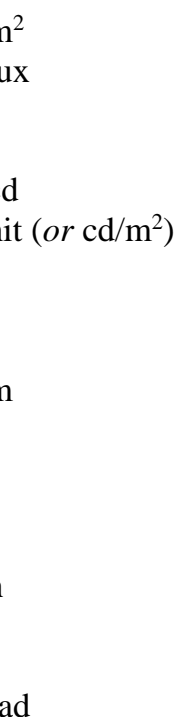

nit $\left(\right.$ or $\left.\mathrm{cd} / \mathrm{m}^{2}\right)$ 


$\begin{array}{lll}\Omega & \text { Corrected solid angle } & \text { rad } \\ \Phi & \text { Luminous flux } & \operatorname{lm} \\ \Phi_{W} & \text { Configuration factor of the window } & -\end{array}$

\section{Main subscripts}

$\begin{array}{ll}b & \text { Background } \\ c & \text { Ceiling } \\ d & \text { Diffuse } \\ f & \text { Flooor } \\ i & \text { i-th } \\ j & \text { j-th } \\ \text { obs } & \text { Obstructed } \\ P & \text { Punctual } \\ r e c & \text { Receiving } \\ s & \text { Source } \\ \text { unobs } & \text { Unobstructed } \\ v & \text { Vertical } \\ v f & \text { Visual field } \\ w & \text { Wall }\end{array}$

\section{Contents}

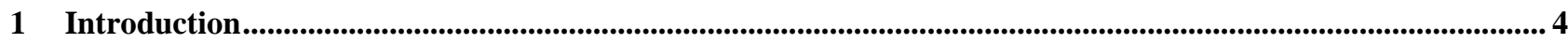

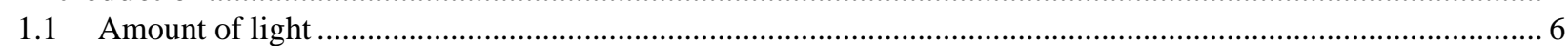

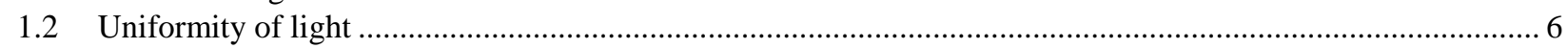

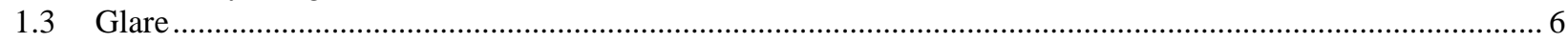

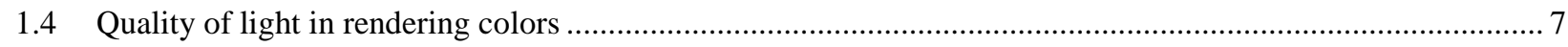

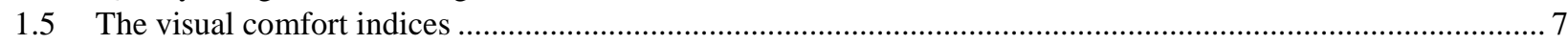

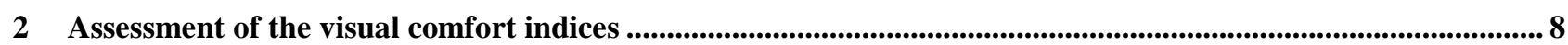

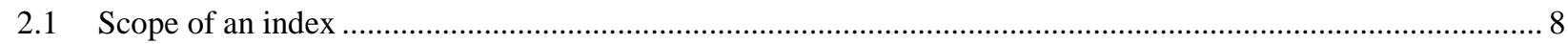

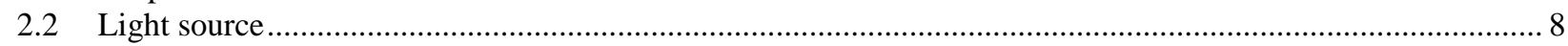

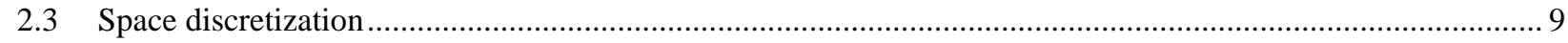

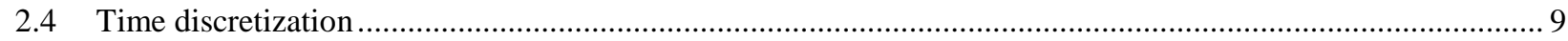

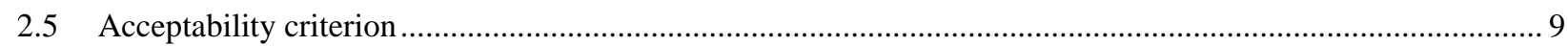

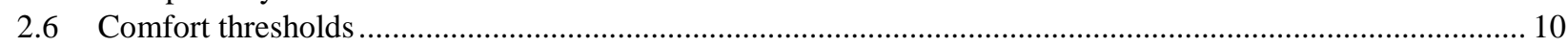

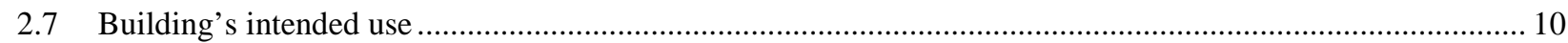

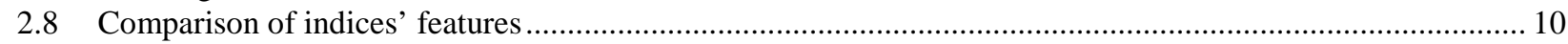

3 Description of the visual comfort indices .............................................................................................................. 12

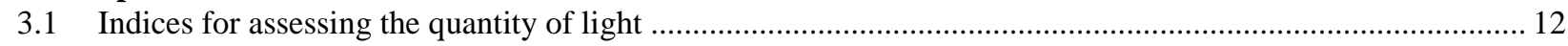

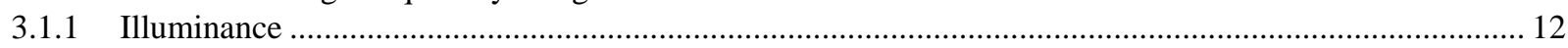

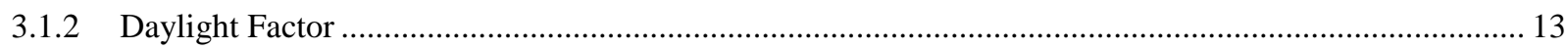

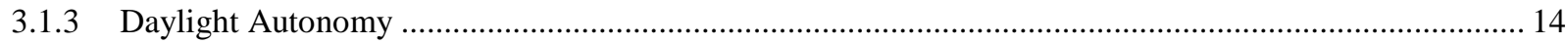

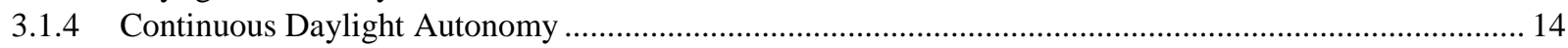

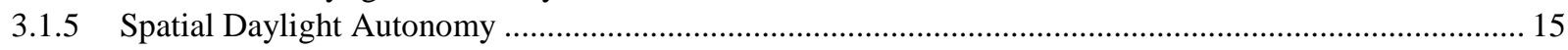

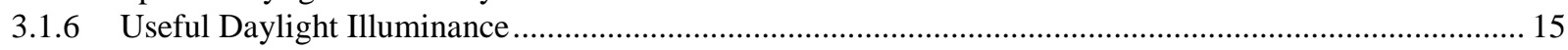

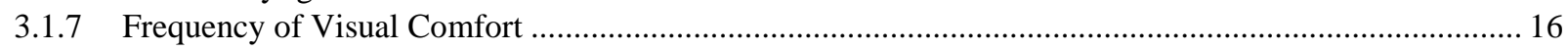

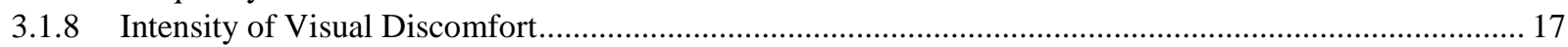

3.2 Indices for assessing the distribution of light ....................................................................................... 17

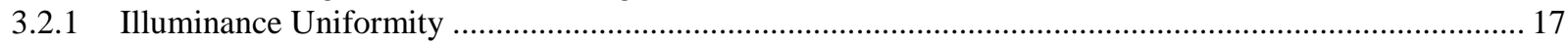




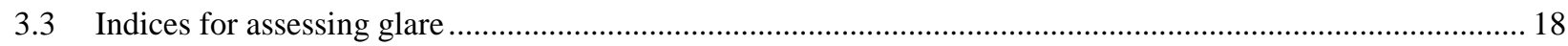

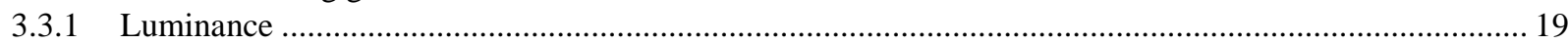

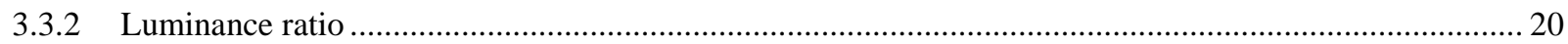

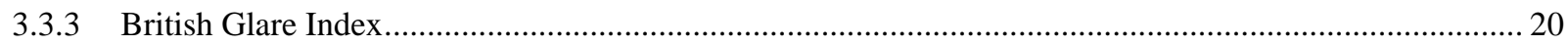

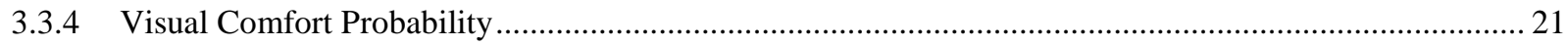

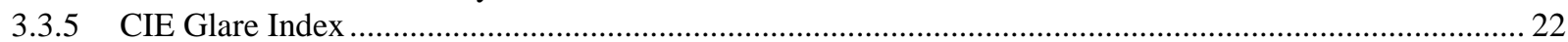

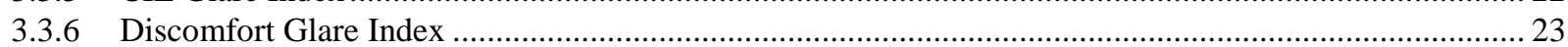

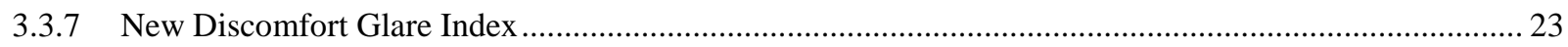

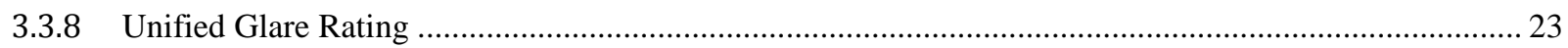

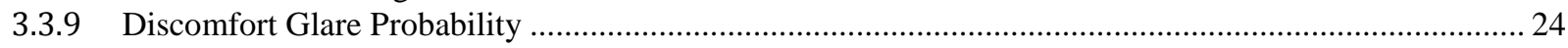

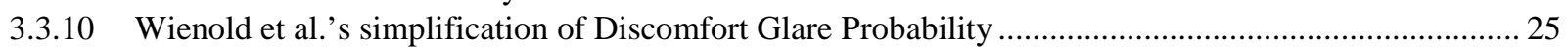

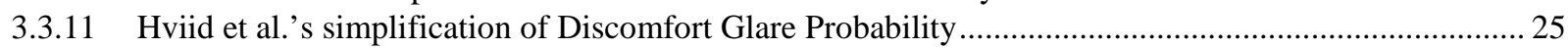

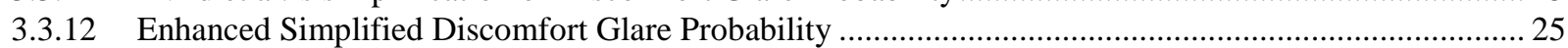

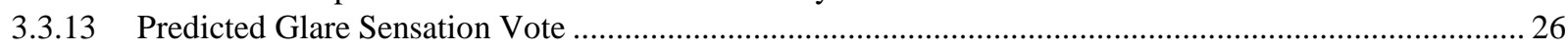

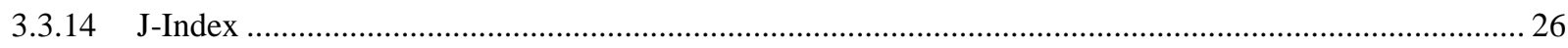

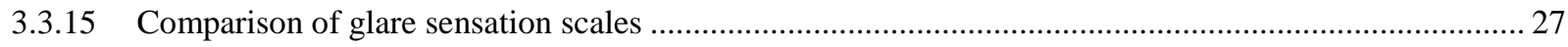

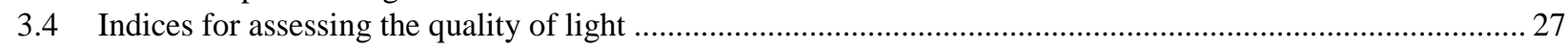

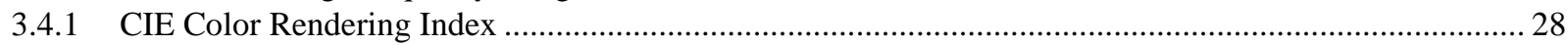

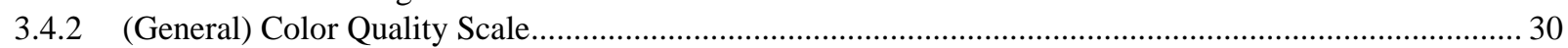

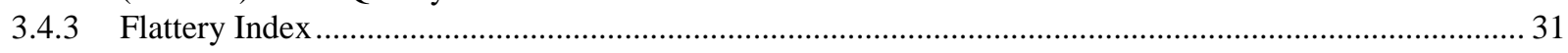

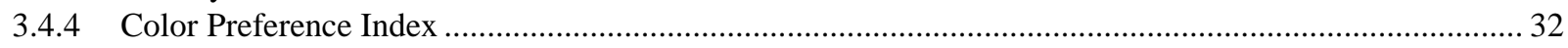

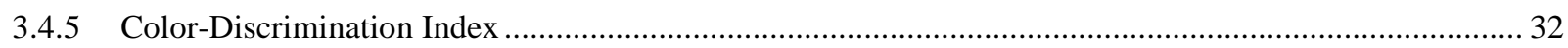

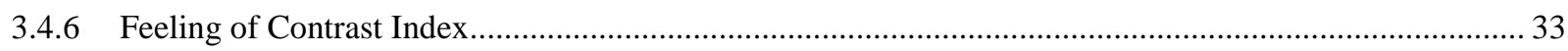

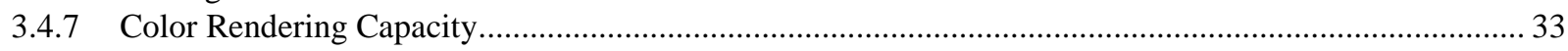

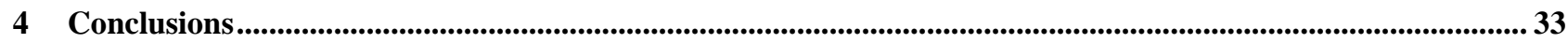

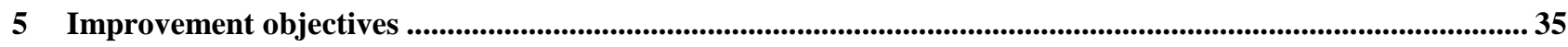

\section{Introduction}

Electrical lighting represents a large amount of energy consumption in the built environment. In an International Energy Agency (IEA) report by Waide and Tanishima [1] it is stated that "worldwide, grid-based electric lighting consumes $19 \%$ of total global electricity production” and that “on average, lighting accounts for $34 \%$ of tertiary-sector electricity consumption and 14 \% of residential consumption in Organisation for Economic Co-operation and Development (OECD) countries. In non-OECD countries these shares are usually higher”. Several other authors report similar values [2-9]. Lighting is moreover responsible for a significant proportion of the maintenance costs in buildings, and most of the current lighting installations (ca. $90 \%$ ) are more than 20 years old, i.e. these installations use antiquated and inefficient lighting equipment [9].

Although the different sources show some discrepancies, and it may be difficult to check and contrast the reported values, they anyway highlight the extremely high weight of lighting in buildings energy consumption [10]. Energy use in buildings for space heating and cooling, ventilation, hot water and lighting has to be drastically reduced in Europe according to EPBD nearly zero energy concept [9], and other countries are moving in similar directions. The absolute value of energy consumption due to electrical lighting inter alia should therefore be substantially lowered, in order to meet European and international targets about energy efficiency in buildings. This should be done maintaining or 
improving the comfort levels. It is hence crucial the availability of commonly agreed, internationally recognized visual comfort indexes.

Three main elements affect the final energy consumption of a lighting system: the lamp (light source, including controls and ballasts), the luminaire, and the room. The lamp transforms electric power into light flux, the luminaire distributes the light in the room, and the room transforms this light into visible luminances by the surface reflections [9].

Also the operating times is affecting the final energy consumption, therefore automatic control, manual control, intelligent architecture and daylight harvesting must be considered in the evaluation of lighting systems, together with maintenance [9].

Many new products have been developed during the last decades both for controls and for lamps and luminaires. Light Emitting Diodes (LED) and Organic Light Emitting Diodes (OLED) are the most important and breakthrough technological innovations already spreading in the market. They will ensure substantial energy saving in the near future [9]. Linhart and Scartezzini [10], moreover, showed that "energy efficient lighting with Lighting Power Density of less than $5 \mathrm{~W} / \mathrm{m}^{2}$ is already achievable in in today’s office rooms without jeopardizing visual comfort and performance”. Li, Cheung [11] report a study where a reduction of $28 \%$ in energy expenditure for electric lighting was obtained using energy-efficient lighting installation and high frequency dimming controls in a school building.

Also a wise use of natural light may help reducing the electrical use for lighting [11]. Because of the high luminous efficacy $[90 \div 120 \mathrm{~lm} / \mathrm{W}$ ] of daylight, also cooling loads may be contained, though this requires an accurate design of the building envelope and interiors.

International environmental performance rating schemes, such as Leadership in Energy and Environmental Design (LEED) [12], include lighting as a key parameter for high performance buildings. For example, LEED assessment involves lighting in four areas: Sustainable Sites, Energy and Atmosphere, Indoor Environmental Quality, and Innovation in Design. Lighting design, in turn, can significantly influence key credits [13]. The Sustainable Site chapter challenges the outdoor light pollution, which is function of the lamp and luminaire efficiency and of the lighting layout. Under the Energy and Atmosphere chapter, lighting is considered together with all the other energy uses in the building, in order to reduce the energy consumption and to provide an adequate measurement and verification. The controllability of lighting systems, daylight and views are instead considered in the Indoor Environment Quality chapter, where design rules and benchmarks are suggested. The Innovation in Design chapter includes the opportunity of accounting for innovative design solutions, if significant, measurable, environmental performance is reported.

Criteria to evaluate energy efficient (natural and artificial) lighting in buildings are the object of ongoing research [14], and, as stated by Linhart and Scartezzini [10], “electricity consumption and energy-efficiency are not the only topics to consider when it comes to designing appropriate lighting scenarios for buildings: good visual comfort is of course equally important”.

The review and classification of indices for assessing visual comfort is therefore a key element for the definition of global performance targets for lighting in buildings. It is moreover useful to develop shared criteria to guide the design of energy efficient systems, able to provide high environmental performance (visual quality) with a low energy consumption. 
Visual comfort is defined in the European standard EN 12665 as "a subjective condition of visual well-being induced by the visual environment” [15]. It depends (i) on the physiology of the human eye, (ii) on the physical quantities describing the amount of light and its distribution in space, and (iii) on the spectral emission of the light source. Visual comfort has been commonly studied through the assessment of some factors characterizing the relationship between the human needs and the light environment, such as (i) the amount of light, (ii) the uniformity of light, (iii) the quality of light in rendering colors, and (iv) the prediction of the risk of glare for occupants.

\subsection{Amount of light}

A good visibility is defined by the presence of an adequate amount of light allowing an occupant to accomplish his tasks. Discomfort can be caused by either too low or too high level of light. The physical quantity usually adopted to quantify the amount of light that reaches a given point of a given surface or work plane is illuminance. It is used either directly or within indices that have it as an input. The calculation of illuminance-based indices usually requires the use of annual weather datasets and delivers an instantaneous or a time-aggregated assessment. These assessments are often carried out by comparing actual light indoor conditions with predefined optimal illuminance ranges or thresholds, which are typically expressed as a function of the task carried out by a typical occupant in a given indoor environment.

\subsection{Uniformity of light}

The uniformity of light describes how evenly light spreads over a task area. A good uniformity of light contributes to avoiding visual stress due to frequent eye adaptations from over-lit to under-lit areas, and thus reduces the risk of visual discomfort. In physical terms, uniformity of light is rendered with uniformity of illuminance on a given task area. It is a useful parameter for describing a given light environment since a simple illuminance average over the entire task area can lead to conclusions that may be similar for very different situations, i.e., a very uniform light distribution and a highly heterogeneous one [16].

\subsection{Glare}

Glare is a light phenomenon that causes a difficulty seeing to the occupants of a luminous environment due to too bright artificial or natural lighting. In general, glare can be defined as "the sensation produced by luminance within the visual field that is sufficiently greater than the luminance to which the eyes are adapted to cause annoyance, discomfort or loss in visual performance and visibility” [17]. It can occur when the amount of light reaching observer's eyes is excessive or when an observer experiences a too wide range of luminance in a given visual field. In the former case, it is called disability glare, or physiological glare, which consists of immediate reduced visual performance and inability to see given objects and the excessive amount of light causes a photophobic response in an observer who reacts squinting, blinking or looking away. Basically, this disturb can be solved reducing the retinal illuminance by darkening a too bright part of the visual field or lowering the luminance of the entire field of view. In the latter case, it is called discomfort glare, or psychological glare, and the excessive contrast between illuminated and dark parts of the visual field causes a progressive degradation of the visual performance and leads to premature tiring of the eyes with a subsequent onset of a feeling of discomfort or other symptoms such as headaches [18]. However, "While disability glare in daylit interiors is relatively 
easy to identify, discomfort glare is a more subtle, subjective phenomenon that is closely linked to a person's overall indoor environmental satisfaction” [19]. Most glare-related indices or metrics aim at evaluating discomfort glare. Basically, glare indices are computed with equations that correlate luminance values, or luminance distributions in the observer's field of view, to human glare sensation. They have been traditionally developed through laboratory experiments with artificial glare sources and only recently also in day-lit spaces [20]. According to Andersen, Kleindienst [16], a reliable prediction of glare with indices still poses important challenges in the building design because: (i) it strongly depends on the observer's position, (ii) tolerance to glare varies depending on the individual, his background, his capability to adapt to the light environment, and (iii) the range of assessed luminance can be very wide.

\subsection{Quality of light in rendering colors}

According to several studies, people are prone to preferring natural light in the living and working spaces [21-24]. It implies great benefits both for health and well being of occupants, by involving perceptive, physiological, psychological, and also economic aspects [25, 26]. Natural light is generally preferred for several reasons: (i) it enhances worker satisfaction and thereby also their productivity [21]; (ii) it allows improved visual quality in terms of the color rendering properties [26]; (iii) it is characterized by changing intensity, direction and even color and these features of daylight connect people to the time of the day [24]; (iv) its use would permit a reduction of the electricity consumption for artificial lighting [25, 27]. At the same time, to date, artificial light is not able to reproduce neither the spectrum, nor the instantaneous variability of daylight [28]. These considerations may lead to a design that just aims at maximizing the utilization of daylight. However, very high daylight availability, e.g., in an office environment, can often prevent from obtaining optimum visual conditions [21]. In fact, excessive daylight can involve too high level of lighting or a nonuniform light environment [27].

\subsection{The visual comfort indices}

Although the aforementioned factors are possibly correlated with each other, an index usually focuses only on one of them. In table 1, a list of 34 indices has been populated based on a search in the scientific literature and the lighting standards. Most of the collected indices are devoted to assessing or predicting firstly glare (17/34; $50 \%$ ), secondly the amount of light (9/34; $26 \%)$; then, the light quality (7/34; $21 \%)$ and lastly the light uniformity (1/34; $3 \%)$. The time evolution of the cumulated number of such indices seems to be far from a saturation state. Figure 1 shows that there was a first surge in the number of the indices for the glare assessment around 1995, a second surge again for the glare indices from 2005 to 2010, and an increased attention was finally devoted to the evaluation of the amount of light in 2012. In the last two decades, research for identifying reliable metrics for evaluating visual comfort has been addressed mostly to glare and the amount of light. 


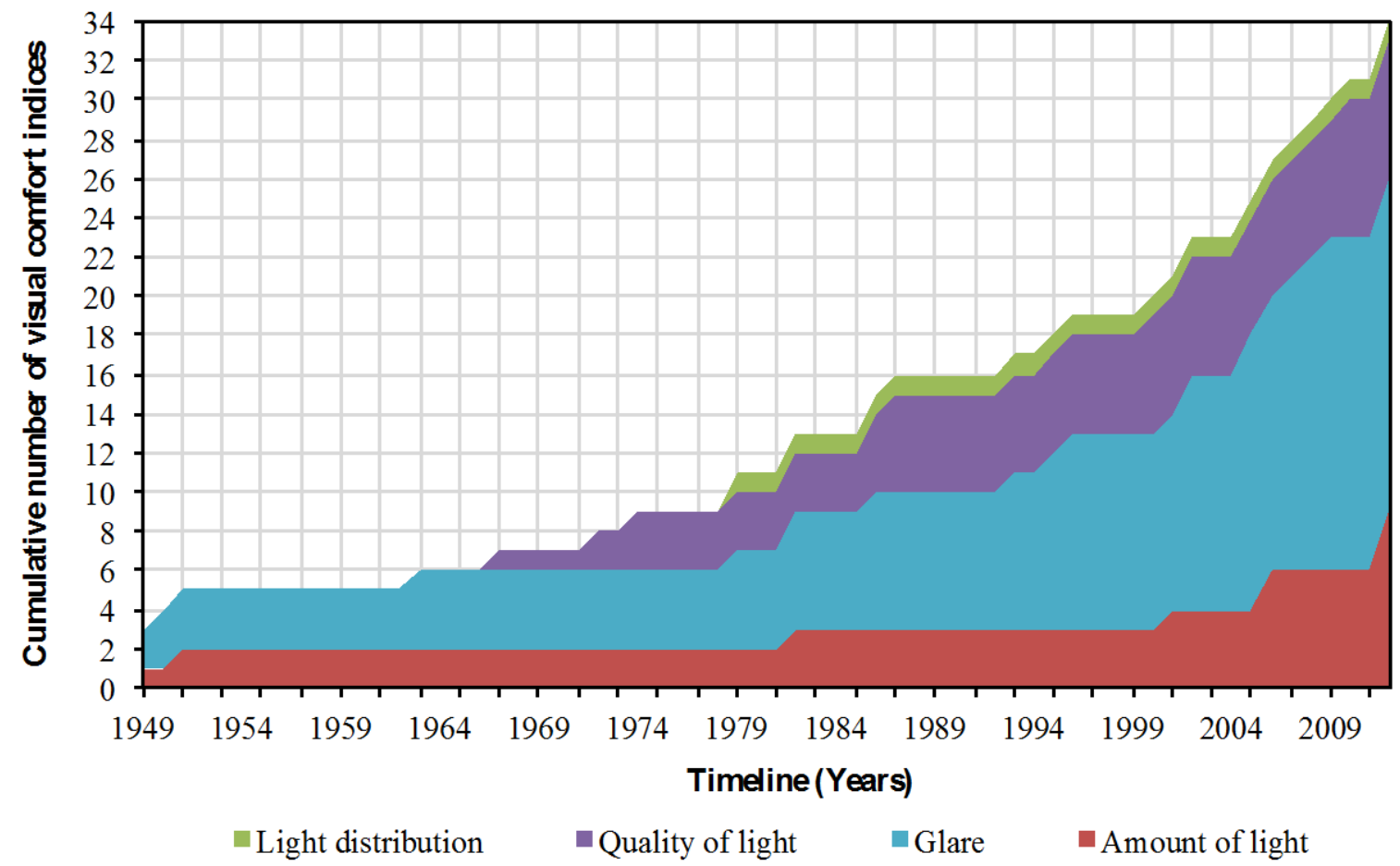

Figure 1 - The cumulative number of visual comfort indices proposed over time.

Thus, none of the today-available metrics can summarize overall visual comfort, characterizing a given light environment, in a single value. In the following sections, an indices’ classification is proposed, along with a critical review.

\section{Assessment of the visual comfort indices}

Many indices aim at evaluating the luminous quality in the built environment, but they differ from each other for several features, such as the scope of the assessment, the physical quantities involved, the calculation period, the light source, the acceptability criterion and the presence of a threshold.

\subsection{Scope of an index}

The different indices have been developed to assess one specified aspect of visual comfort, i.e., amount of light, light uniformity, light quality and glare. This information helps in grouping easily the indices in families.

\subsection{Light source}

Indices are proposed for tackling specific problems. Their mathematical structures have been developed according to assumptions that could restrict their application to environments lit with just natural light, just artificial light or both. This information is useful to guide quickly towards the identification of the most suitable index or group of indices. 


\subsection{Space discretization}

A possible classification can be based on the space discretization of the calculation output. From this perspective, indexes can be local or zonal. A local index varies with position thus providing a value for each point inside a space; local indices are often presented through maps, which deliver a detailed visualization of the index magnitude over the whole space. A zonal index, on the other hand, provides a single value representing the whole environment under analysis (e.g., a room). The former indices can support designers in the detailed definition of shape and location of windows or skylights while the latter ones are useful to communicate with non-specialists and to be passed to other analysis techniques (e.g., optimization, sensitivity analysis, uncertainty analysis etc.).

\section{$2.4 \quad$ Time discretization}

In the literature, a number of adjectives or terms are used for describing the type of assessment delivered by a visual comfort index depending on the time discretization. Reinhart, Mardaljevic [29] use the adjectives dynamic and static to identify those indices that are respectively based on time-series of illuminance or luminance values, or just involve a given climatic condition considered representative for a given situation. The dynamic approach is adopted to return a comprehensive result for the building performance and to account for variations in the sky and weather conditions. They are basically computed over a calendar year through building performance software that, usually, accounts for the use of building and control strategies. Moreover, according to Mardaljevic, Heschong [30] the dynamic indices can be further divided into two categories: time-series indices, which provide a series of instantaneous measures based on the hourly values in the annual weather dataset, and cumulative indices, which predict aggregated measures of daylight over a period of the time. In the analogy to the terminology usually adopted in the thermal comfort field [31], visual comfort indices are assessed here by adopting the terms short-term and long-term. Short-term are those indices that deliver an instantaneous assessment of a given light environment; long-term are, instead, those indices that summarize in a single value an assessment of a given light environment over an extended period of the time.

\subsection{Acceptability criterion}

A number of indices assess a given light environment by comparing the actual values of one or more physical quantities with given reference values. The acceptance criterion can be one-tailed or two-tailed. For the one-tailed indices, a level of visual performance is considered acceptable when the physical quantity is greater or smaller than one reference value. Otherwise, in two-tailed indices, two boundary values are set so that only the cases that fall inside (or outside) those values are considered acceptable. Indices related with glare, color rendering and light uniformity mainly fit in the former category, since their acceptable level is generally assumed to be simply greater or smaller than a defined threshold. On the other hand, the latter category suits illuminance-based metrics since at least some of them consider whether there is too low or too high illuminance that may generate visual discomfort [32]. 


\subsection{Comfort thresholds}

Some indices are accompanied by thresholds, which are useful in determining whether a given luminous environment can be considered comfortable. However, the definition of a threshold is critical since it can depend on the assessed phenomenon, the visual task carried out by occupants, and the lighting technique. Generally, most illuminance-based indices suggest threshold values that vary depending on the visual task. Instead, glare-related indices are accompanied by fixed threshold values since they are usually derived from studies, which analyzed the physiological response of people to predefined luminous stimuli.

\subsection{Building's intended use}

As far as thermal comfort is concerned, the adoption of metrics can depend on whether a building is equipped with a mechanical cooling system or uses natural ventilation to cool down its indoor environment during summer. Therefore, in some cases, specific features of a building can drive the choice of a metric or an assessment method. For this reason, the potential relationship between visual comfort metrics and building's intended use is here discussed. In this paper 33 visual comfort metrics are presented and for most of them the authors do not signal an explicit relationship to building types. For only six indices, five dealing with glare and one with the light quantity, their authors have explicitly stated that they are developed from field measurements carried out in offices [20, 32-35] or office-like test chambers [36]. Instead, Hopkinson [37] validates a glare metric using data measured in hospitals wards and school classrooms. However it should be noted that for none of such indexes the respective authors give specific recommendations in terms of application only to a specific building type. This might lead to the consideration that the evaluation of visual comfort is not strongly driven by the buildings' intended use itself. Furthermore, the same metrics have been used for assessing visual conditions in different building types such as offices [30, 38-41], industrial buildings [42, 43], commercial buildings or commercial building-like facilities [44, 45], schools or universities [46, 47], hospitals and healthcare facilities [48-50], residential buildings [30, 51]. Finally, the European standard EN 12464-1 [52] presents reference values for the amount of light (using illuminance), glare (using Unified Glare Rating), uniformity of light (using Illuminance Uniformity) and color rendering quality of artificial light (using Color Rendering Index) as related rather to the "Type of area, task or activity" [52]. Based on the literature reviewed visual comfort indexes appear not to be significantly dependent on building's intended use, but they might rather be determined by the specific visual task or activity that has to be performed in terms of light quantity, distribution, quality and glare.

\subsection{Comparison of indices' features}

In table 1, a graphical summary of aforementioned indices' features is reported. It can be observed that more recent indices are prevalently long-term ones: this fact can be interpreted as a need for wrapping up in a single parameter some of the time-varying characteristics of a luminous environment. Moreover, the presence of reliable long-term indices can help the increasing adoption of an optimization-based building design, which uses such indices as objective functions.

Table 1 - Summary of the features of identified comfort indexes. 


\begin{tabular}{|c|c|c|c|c|c|c|c|}
\hline Source & $\begin{array}{l}\text { Visual comfort } \\
\text { metric }\end{array}$ & $\begin{array}{l}\text { Scope of the } \\
\text { index }\end{array}$ & Light source & $\begin{array}{l}\text { Space } \\
\text { discretization }\end{array}$ & $\begin{array}{l}\text { Time } \\
\text { discretization }\end{array}$ & $\begin{array}{l}\text { Acceptability } \\
\text { criterion }\end{array}$ & $\begin{array}{l}\text { Presence } \\
\text { of a } \\
\text { comfort } \\
\text { threshold }\end{array}$ \\
\hline Not defined & Illuminance $\left(E_{P}\right)$ & Amount of light & $\begin{array}{l}\text { Natural } \\
\text { Artificial }\end{array}$ & Local & Short-term & One-tailed & Yes \\
\hline Not defined & Luminance $(L)$ & Glare & $\begin{array}{l}\text { Natural } \\
\text { Artificial }\end{array}$ & Local & Short-term & One-tailed & Yes \\
\hline Not defined & Luminance ratio & Glare & $\begin{array}{l}\text { Natural } \\
\text { Artificial }\end{array}$ & Local & Short-term & One-tailed & Yes \\
\hline $\begin{array}{l}\text { Petherbridge and } \\
\text { Hopkinson [53] }\end{array}$ & $\begin{array}{l}\text { British Glare Index } \\
(B G I)\end{array}$ & Glare & Artificial & Local & Short-term & One-tailed & Yes \\
\hline Walsh [54] & $\begin{array}{l}\text { Daylight Factor } \\
(D F)\end{array}$ & Amount of light & Natural & $\begin{array}{l}\text { Local } \\
\text { Zonal }\end{array}$ & Short-term & One-tailed & Yes \\
\hline Guth [55] & $\begin{array}{l}\text { Visual Comfort } \\
\text { Probability }(V C P)\end{array}$ & Glare & Artificial & Local & Short-term & One-tailed & Yes \\
\hline Judd [56] & Flattery Index $\left(R_{f}\right)$ & Light quality & Artificial & Not applicable & Short-term & Not applicable & Yes \\
\hline Thornton [57] & $\begin{array}{l}\text { Color } \\
\text { Discrimination } \\
\text { Index }\end{array}$ & Light quality & Artificial & Not applicable & Short-term & Not applicable & Yes \\
\hline Thornton [58] & $\begin{array}{l}\text { Color Preference } \\
\text { Index }\end{array}$ & Light quality & Artificial & Not applicable & Short-term & Not applicable & Yes \\
\hline DIN 5035 [59] & $\begin{array}{l}\text { Illuminance } \\
\text { Uniformity }\left(U_{O}\right)\end{array}$ & Light distribution & $\begin{array}{l}\text { Natural } \\
\text { Artificial }\end{array}$ & Zonal & Short-term & Not applicable & Yes \\
\hline Einhorn [60] & $\begin{array}{l}\text { CIE Glare Index } \\
(C G I)\end{array}$ & Glare & $\begin{array}{l}\text { Natural } \\
\text { Artificial }\end{array}$ & Local & Short-term & One-tailed & Yes \\
\hline Chauvel, Collins [61] & $\begin{array}{l}\text { Discomfort Glare } \\
\text { Index }(D G I)\end{array}$ & Glare & Artificial & Local & Short-term & One-tailed & Yes \\
\hline $\mathrm{Xu}[62]$ & $\begin{array}{l}\text { Color Rendering } \\
\text { Capacity }\end{array}$ & Light quality & Artificial & Not applicable & Short-term & Not applicable & No \\
\hline Pointer [63] & $\begin{array}{l}\text { Pointer's color } \\
\text { rendering index }\end{array}$ & Glare & Artificial & Local & Short-term & One-tailed & Yes \\
\hline CIE 17.4 [64] & $\begin{array}{l}\text { Color Rendering } \\
\text { Index }(C R I \text { or } R a)\end{array}$ & Light quality & Artificial & Not applicable & Short-term & Not applicable & Yes \\
\hline Meyer, Francioli [65] & J-Index & Glare & Artificial & Local & Short-term & Not applicable & No \\
\hline CIE 17 [66] & $\begin{array}{l}\text { Unified Glare } \\
\text { Rating (UGR) }\end{array}$ & Glare & Artificial & Local & Short-term & One-tailed & Yes \\
\hline Tokura, Iwata [36] & $\begin{array}{l}\text { Predicted Glare } \\
\text { Sensation Vote } \\
(P G S V)\end{array}$ & Glare & Artificial & Local & Short-term & One-tailed & No \\
\hline Hashimoto, Yano [67] & $\begin{array}{l}\text { Feeling of Contrast } \\
\text { Index }\end{array}$ & Light quality & Artificial & Not applicable & Short-term & Not applicable & Yes \\
\hline $\begin{array}{l}\text { Reinhart and } \\
\text { Walkenhorst [38] }\end{array}$ & $\begin{array}{l}\text { Daylight Autonomy } \\
(D A)\end{array}$ & Amount of light & Natural & Local & Long-term & One-tailed & No \\
\hline CIE 146/147 [68] & $\begin{array}{l}\text { Unified Glare } \\
\text { Rating for small } \\
\text { light sources }\end{array}$ & Glare & Artificial & Local & Short-term & One-tailed & Yes \\
\hline CIE 146/147 [68] & $\begin{array}{l}\text { Great-room Glare } \\
\text { Rating (GGR) }\end{array}$ & Glare & Artificial & Local & Short-term & One-tailed & Yes \\
\hline
\end{tabular}




\begin{tabular}{|c|c|c|c|c|c|c|c|}
\hline Nazzal [21] & $\begin{array}{l}\text { New Discomfort } \\
\text { Glare Index }\left(D G I_{N}\right)\end{array}$ & Glare & Artificial & Local & Short-term & One-tailed & No \\
\hline $\begin{array}{l}\text { Wienold and } \\
\text { Christoffersen [69] }\end{array}$ & $\begin{array}{l}\text { Discomfort Glare } \\
\text { Probability }(D G P)\end{array}$ & Glare & $\begin{array}{l}\text { Natural } \\
\text { Artificial }\end{array}$ & Local & Short-term & One-tailed & Yes \\
\hline $\begin{array}{l}\text { Nabil and Mardaljevic } \\
\text { [32] }\end{array}$ & $\begin{array}{l}\text { Useful Daylight } \\
\text { Illuminance (UDI) }\end{array}$ & Amount of light & Natural & Local & Long-term & Two-tailed & No \\
\hline $\begin{array}{l}\text { Rogers and Goldman } \\
\text { [70] }\end{array}$ & $\begin{array}{l}\text { Continuous } \\
\text { Daylight Autonomy } \\
\text { (DAcon) }\end{array}$ & Amount of light & Natural & Local & Long-term & One-tailed & No \\
\hline Wienold, Jiang [33] & $\begin{array}{l}\text { Wienold's } \\
\text { Simplified } \\
\text { Discomfort Glare } \\
\text { Probability (DGPs) }\end{array}$ & Glare & $\begin{array}{l}\text { Natural } \\
\text { Artificial }\end{array}$ & Local & Short-term & One-tailed & No \\
\hline Hviid, Nielsen [34] & $\begin{array}{l}\text { Hviid's } \\
\text { simplification of the } \\
\text { Discomfort Glare } \\
\text { Probability (DGPs) }\end{array}$ & Glare & $\begin{array}{l}\text { Natural } \\
\text { Artificial }\end{array}$ & Local & Short-term & One-tailed & No \\
\hline Wienold [35] & $\begin{array}{l}\text { Enhanced } \\
\text { Simplified } \\
\text { Discomfort Glare } \\
\text { Probability (eDGPs) }\end{array}$ & Glare & $\begin{array}{l}\text { Natural } \\
\text { Artificial }\end{array}$ & Local & Short-term & One-tailed & No \\
\hline Davis and Ohno [71] & Color Quality Scale & Light quality & Artificial & Not applicable & Short-term & Not applicable & Yes \\
\hline Sicurella, Evola [72] & $\begin{array}{l}\text { Frequency of Visual } \\
\text { Comfort }(F V C)\end{array}$ & Amount of light & Natural & Zonal & Long-term & Two-tailed & Yes \\
\hline Sicurella, Evola [72] & $\begin{array}{l}\text { Intensity of Visual } \\
\text { Discomfort (IVD) }\end{array}$ & Amount of light & Natural & Zonal & Long-term & Two-tailed & Yes \\
\hline IES [73] & $\begin{array}{l}\text { Spatial Daylight } \\
\text { Autonomy (sDA) }\end{array}$ & Amount of light & Natural & Zonal & Long-term & One-tailed & No \\
\hline
\end{tabular}

\section{Description of the visual comfort indices}

Reliable indices are needed in a design process for assessing the quality of the visual environment. Although a number of reviews about visual comfort indices are available in the literature [19, 27, 29, 74-76], none of them reports the indices dealing with the four factors involved in visual comfort altogether. Moreover, there is no general agreement on methodology and metrics to evaluate the individual factors of visual comfort. Therefore, a literature and standards analysis has been conducted, looking for visual comfort metrics, including advantages and limitations associated to their use. We hope that the analysis framework developed in this paper might contribute to developing new enhanced indices that can evaluate more than one aspect of visual comfort, in order to be easily integrated into a comfort-based optimization procedure.

\subsection{Indices for assessing the quantity of light}

\subsubsection{Illuminance}

Illuminance at a point $P$ of a given surface is a physical quantity, measured in lux and defined as the ratio between the luminous flux incident on an infinitesimal surface in the neighborhood of $P$ and the area $\left(A_{\text {rec }}\right)$ of that surface. 


$$
E_{p}=\frac{d f}{d A_{r e c}} \quad[l x]
$$

This definition, being referred to the illuminated surface and the luminous flux on the entire range of light wavelengths, is independent of the type and features of the light source(s). Illuminance is used to construct a local and short-term metric assessing the amount of light with a one-tailed criterion. Different illuminance thresholds are associated to the different building typologies and kind of uses of spaces in a building. In a typical office use, the European standard EN 12464-1 [77] and most authors suggest a reference value of $500 \mathrm{~lx}$ evaluated on the work-plane [78-81]; while others consider sufficient 425 lx [6] or even 300 lx [82].

Such approach has the advantage of being simple and immediate since it takes just a luxmeter to measure the amount of light, thus allowing simple and direct ex post evaluations. However, there are some limitations when the objective is the evaluation of the overall performance of a space: (i) the measure is local and depends on the orientation of the lit surface, (ii) it is a short-term quantity, i.e., it does not consider variations over time and has to be repeated for every time step, leading to voluminous time-series in order to deal with long-term assessments, (iii) it does not take into account the nature of light, be it artificial or from the sun, (iv) it cannot deal with glare since it is independent of the observer.

\subsubsection{Daylight Factor}

Trotter presented the Daylight Factor (DF) for the first time in 1895 [54]. It is "the ratio of the daylight illumination at a given point on a given plane due to the light received directly or indirectly from the sky of assumed or known luminance distribution to the illumination on a horizontal plane due to an unobstructed hemisphere of this sky. Direct sunlight is excluded for both interior or exterior values of illumination” [22].

$$
D F=\frac{E_{p, o b s}}{E_{P, u t w b s}},
$$

where $E_{P, o b s}$ is the horizontal illuminance at a point $P$ due to the presence of a room that obstructs the view of the sky and $E_{P, \text { unobs }}$ is the horizontal illuminance at the same point $P$ if the view of the sky is unobstructed by the room. As the name suggests, only natural light is considered.

Since daylight is intrinsically variable over time, this metric was based on such ratio in order to avoid the dependency of the daylight performance on the instantaneous sky conditions [29]. The initial assumption of uniform luminance across the sky dome under heavily overcast sky was overtaken by [83], who proposed a formulation for the luminance pattern of overcast skies that was adopted as a standard by the Commission Internationale de l'Eclairage (CIE) in 1955 [84].

$D F$ is used to construct a short-term index assessing the amount of light with a one-tailed criterion. Threshold values depend on the intended use of the lighted zone. Typical values derive from the assumption that, under an overcast sky, the outside illuminance lies around $10000 \mathrm{~lx}$ while $500 \mathrm{~lx}$ on the work plane are often recommended for office work, so that the ratio is about $2 \%$. However, several standards provide different thresholds. $D F$ is computed at a given point of a work plane, but it is often accompanied by rules for averaging it over wide surfaces like a whole room. Using these averaging rules, this index can be used for assessing a building zone and becomes zonal. $D F$ values of at least $5 \%$ are advised for "not too deep or obstructed office rooms" [85] while a DF value of $2 \%$ is considered sufficient for residences. 
The British Standard Institution proposes even smaller minimum values such as $1.0 \%$ in bedrooms, $1.5 \%$ in living rooms, and $2.0 \%$ in kitchens [86].

According to several authors, $D F$ has some noticeable limitations: (i) it cannot properly represent non-overcast skies since, basically, the actual daylight illumination conditions significantly differ from the overcast sky model [30], (ii) it is expressed as a percentage, hence it does not consider absolute illuminance values [30], (iii) in building design, maximizing $D F$ leads to admit as much daylight as possible by means of building envelopes with a large ratio of glazed area over opaque area [29] which can affect the thermal comfort performance of the building, and (iv) the orientation of a building has no effect on $D F$ calculation [87]. Cantin and Dubois [25] remark that another limitation of $D F$ is that it cannot assess discomfort glare since does not consider lighting of the walls, which is critical for human perception. However, it should be noticed that the glare assessment is outside of the scope of this index.

\subsubsection{Daylight Autonomy}

Daylight Autonomy (DA) was firstly proposed by the Association Suisse des Electriciens in 1989 [88] and was refined by Reinhart and Walkenhorst [38]; it is defined as the percentage of the occupied hours of the year when a minimum illuminance threshold is met by the sole daylight.

$$
\begin{gathered}
D A=\frac{\sum_{i}\left(w f_{i} \cdot t_{i}\right)}{\sum_{i} t_{i}} \in[0,1] \\
\text { with } w f_{i}=\left\{\begin{array}{lll}
1 & \text { if } \quad E_{\text {Daytight }} \geq E_{\text {limit }} \\
0 & \text { if } \quad E_{\text {Dewight }}<E_{\text {limit }}
\end{array},\right.
\end{gathered}
$$

where $t_{i}$ is each occupied hour in a year; $w f_{i}$ is a weighting factor depending on values of $E_{\text {Daylight }}$ and $E_{\text {limit }}$ that are, respectively, the horizontal illuminance at a given point due to the sole daylight and the illuminance limit value. The definition of $D A$ is not accompanied by a specified threshold value; Olbina and Beliveau [89] suggest setting the $E_{\text {limit }}$ threshold at $500 \mathrm{~lx}$.

$D A$ is a long-term, one-tailed and local index referred to the amount of natural light available at a given point of the space during occupied hours. It conceives the visual performance through a single value expressed as a percentage. $D A$ takes into account the real weather conditions at the site. However, according to Nabil Nabil and Mardaljevic [32], it has some limitations: (i) $D A$ does not give significance to the daylight illuminance values that fall below the threshold, but which can be valued by occupants and may also reduce the electric lighting loads; (ii) being one-tailed, it makes no account of the amount by which the threshold is exceeded and whether this might be potentially a cause of visual discomfort due to an excess of light.

\subsubsection{Continuous Daylight Autonomy}

Continuous Daylight Autonomy ( $\left.D A_{C O N}\right)$ is an amelioration of $D A$ proposed by Rogers and Goldman [70]. In contrast to earlier definitions of $D A$, partial credit is attributed to time-steps when the measured daylight illuminance $\left(E_{\text {daylight }}\right)$ lies below the limit ( $\left.E_{\text {limit }}\right)$. 


$$
\begin{aligned}
& D A_{C O N}=\frac{\sum_{i}\left(w f_{i} \cdot t_{i}\right)}{\sum_{i} t_{i}} \in[0,1]
\end{aligned}
$$

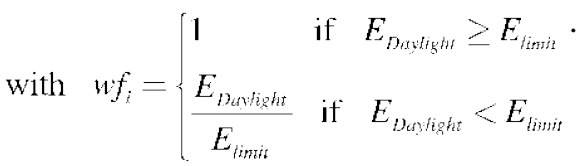

This metric acknowledges that even a partial contribution of daylight to illuminate a space is still beneficial and assumes the benefit to growing linearly with the level of illuminance.

$D A_{C O N}$ is a long-term and local index referred to the amount of natural light available at a given point of the space during occupied hours and is a one-tailed index.

\subsubsection{Spatial Daylight Autonomy}

Spatial Daylight Autonomy ( $s D A$ ) is "a metric describing annual sufficiency of ambient daylight levels in interior environments" and is defined as "the percent of an analysis area [...] that meets a minimum daylight illuminance level for a specified fraction of the operating hours per year” [73]. The calculation is performed assessing DA as defined in [38], in each point of a spatial grid over the area of interest, and then only those points, with $D A$ not minor than a given reference value, are included in the summation, increasing the value of $s D A$. Its formulation is

$$
\begin{aligned}
& s D A_{x i y, 1}=\frac{\sum_{i}\left(w f_{i} \cdot D A\right)}{\sum_{i} p_{i}} \in[0,1] \\
& \text { with } w f_{i}=\left\{\begin{array}{ll}
1 & \text { if } D A \geq D A_{\text {timit }} \\
0 & \text { if } D A<D A_{\text {timir }}
\end{array},\right.
\end{aligned}
$$

where $x$ is the reference illuminance level, $y$ is the time fraction, $p_{i}$ are the points belonging to the calculation grid. Illuminating Engineering Society (IES) recommends $s D A_{300 / 50} \%$ for analysis of daylight sufficiency, expressing the percentage of points of the analyzed area which meet or exceed the horizontal illuminance threshold of 300 lx for at least $50 \%$ of the occupied hours (evaluated from 8 a.m. to 6 p.m. of the local clock time) over a typical meteorological year [73].

$s D A$ is a long-term, zonal, one-tailed index assessing the amount of natural light. The main advantage over traditional $D A$ is that $s D A$ returns a single value representing the whole analyzed area. However, similarly to $D A$, it makes no account of the amount by which the illuminance threshold is exceeded.

\subsubsection{Useful Daylight Illuminance}

Useful Daylight Illuminance (UDI) is defined as the fraction of the time in a year when indoor horizontal daylight illuminance at a given point falls in a given range. A lower and an upper illuminance limit values are proposed in order to split the analyzed period into three bins: the upper bin is meant to represent the percentage of the time when an oversupply of daylight might lead to visual discomfort, the lower bin represents the percentage of the time when there is too little daylight, and the intermediate bin represents the percentage of the time with appropriate illuminance level. 


$$
\begin{aligned}
& U D I=\frac{\sum_{i}\left(w f_{i} \cdot t_{i}\right)}{\sum_{i} t_{i}} \in[0,1]
\end{aligned}
$$

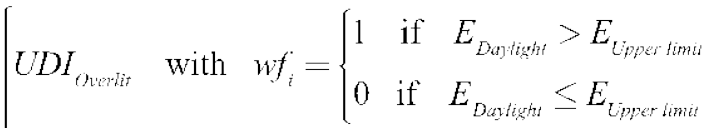

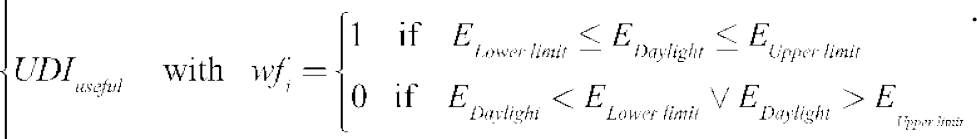

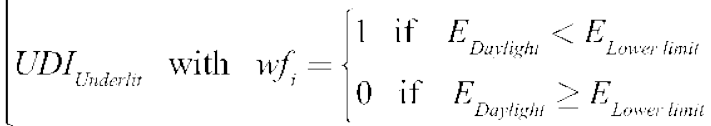

Illuminance limit values vary depending on the authors as reported in table 2.

Table 2: UDI illuminance limit values

\begin{tabular}{lll}
\hline Source & $\begin{array}{l}\text { Lower illuminance limit } \\
(\mathbf{l x})\end{array}$ & $\begin{array}{l}\text { Upper illuminance limit } \\
(\mathbf{( x )})\end{array}$ \\
\hline Nabil and Mardaljevic [32] & 100 & 2000 \\
Mardaljevic, Heschong [30] & 100 & 2500 \\
Olbina and Beliveau [89] & 500 & 2000 \\
David, Donn [82] & 300 & 8000 \\
\hline
\end{tabular}

$U D I$ is a long-term, local and two-tailed index that measures the quantity of natural light. According to Nabil and Mardaljevic [32], UDI informs not only on useful levels of daylight illuminance, but also on the frequency of occurrence of excessive levels of daylight that might cause occupant discomfort (i.e., glare) and unwanted solar gains. Possible limitations are: (i) there is no full agreement on illuminance limit values; (ii) UDI provides three values for each point of the space.

\subsubsection{Frequency of Visual Comfort}

Frequency of Visual Comfort $(F V C)$ is defined in [72] as the percentage of the time within a given period during which daylight alone delivers appropriate values of illuminance. It is assumed that if average illuminance stays in the range between two threshold values, then visual comfort is guaranteed thanks to daylight only. The equation to calculate FVC is

$$
\begin{gathered}
F V C=\frac{\sum_{i}\left(w f_{i} \cdot t_{i}\right)}{\sum_{i} t_{i}} \in[0,1] \\
\text { with } w f_{i}= \begin{cases}1 & \text { if } E_{\text {Under }} \leq E_{\text {Davight }} \leq E_{\text {Over }} \\
0 & \text { if } E_{\text {Daylight }}<E_{\text {Qnder }} \vee E_{\text {Davlight }}>E_{\text {Over }}\end{cases}
\end{gathered}
$$


Whenever illuminance is below $E_{\text {Under }}$ or above $E_{\text {Over }}$, daylighting is respectively insufficient, i.e., occupants are obliged to use artificial lighting, or excessive, i.e., glare may occur. The definition of the range of visual comfort is critical as it depends on many factors, such as the actual working context, the visual task, the background luminance etc. The authors assume as satisfactory a value of $F V C$ higher than 0.8 , that is a situation where illuminance values are outside the range $\left(E_{\text {Under }}=150 \mathrm{~lx}, E_{\text {Over }}=750 \mathrm{~lx}\right)$ at most for $20 \%$ of the time.

FVC is a long-term, two-tailed and zonal index assessing natural amount of light. According to its authors, FVC is useful to compare the global visual effectiveness of different technical solutions and systems (for daylight control and exploitation) on a monthly or annual basis. The concept behind the definition of FVC is similar to UDI, but the values of $E_{\text {Over }}$ and $E_{\text {Under }}$ are different in respect to what is proposed in [32], i.e., $2000 \mathrm{~lx}$ and $100 \mathrm{~lx}$, respectively. These values are probably proposed because Sicurella, Evola [72] work on a spatial-averaged daylight illuminance and not on a spatial distribution of values, thus a narrower range could better guarantee to avoid too high or too low values locally. However, the averaging procedure is not described.

\subsubsection{Intensity of Visual Discomfort}

Intensity of Visual Discomfort (IVD) is defined in [72] and consists of two indices, IVD ${ }_{\text {Over }}$ and IVD Under that result, respectively, from the time integral of the difference between the spatial average of current daylight illuminance and the upper limit of visual comfort ( $E_{\text {Over }}$ is set at $750 \mathrm{~lx}$ ) or the lower limit of visual comfort ( $E_{\text {Under }}$ is set at $150 \mathrm{~lx}$ ). The calculation is performed according to

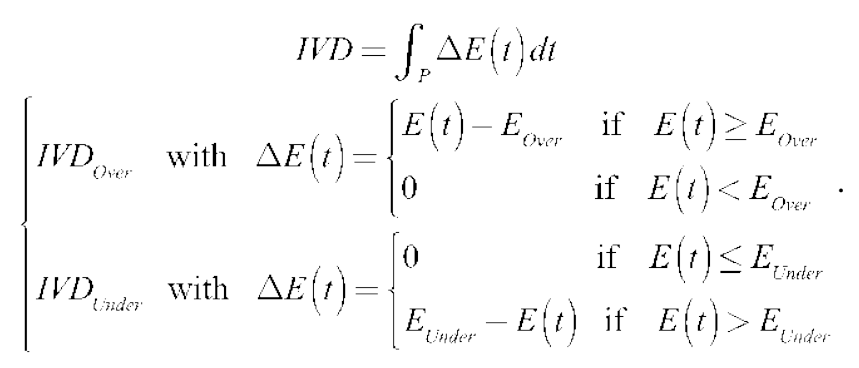

As $I V D_{\text {Over }}$ and $I V D_{\text {Under }}$ get higher, the visual discomfort for excessive or insufficient daylight is more important. $I V D$ assesses the quantity of natural light, and it is a zonal and long-term index. The two individual indices can be seen as onetailed, but the IVD approach can be considered a two-tailed method since it considers both over-lit and under-lit situations. The authors propose a comfort threshold according to this criterion: illuminance limits $E_{\text {Over }}$ and $E_{\text {Under }}$ can be overcome in any case for not more than the $30 \%$ of their value. Since the averaging procedure is not explicitly described, it would be advisable to make it explicit and/or to accompany this index with an assessment of the light uniformity.

\subsection{Indices for assessing the distribution of light}

\subsubsection{Illuminance Uniformity}

Visual comfort is associated not only to the amount of light in a space, but also to its distribution. Illuminance Uniformity $\left(U_{O}\right)$ of a given plane is defined as the ratio, in a given moment, between the minimum value of the illuminance on the plane $\left(E_{\min }\right)$ and the average illuminance on that plane $\left(E_{\text {average }}\right)$. It is also possible to use the ratio between the minimum 
and the maximum $\left(E_{\max }\right)$ values of illuminance on the given plane, but this has to be specified [77]. Their formulations are respectively

$$
\begin{gathered}
U_{O, \text { alerage }}=\frac{E_{\text {mith }}}{E_{\text {average }}} \\
U_{o, \max }=\frac{E_{\text {min }}}{E_{\text {max }}} .
\end{gathered}
$$

$U_{O}$ is a short-term and zonal index assessing the uniformity of light. As far as threshold values are concerned, a list of some recommended uniformity ratios (table 3) is provided in [90] and reported in [91].

Table 3: Illuminance Uniformity recommended in standards for indoor spaces, reproduced from [90].

\begin{tabular}{ll}
\hline Source & Illuminance uniformity over task \\
\hline AS 1680 [92] & $U_{\text {O,average }}>0.67$ \\
DIN 5035 [59] & $U_{\text {O,average }}>0.67$ \\
NSVV [93] & $U_{\text {O,average }}>0.7$ \\
CIBSE [94] & $U_{\text {O,average }}>0.8$ \\
BS 8206-1 [95] & $U_{\text {O,average }}>0.8$ \\
CIE 29.2 [96] & $U_{\text {O,max }}>0.7$ \\
\hline
\end{tabular}

In summary, many lighting standards require a uniformity ratio of 0.8 (min/average) or 0.7 (min/max) [91]. EN 12464-1 provides also a series of minimum values to be maintained outside the task area. In the adjacent 'immediate surrounding area', values ranging from 0.4 to 0.7 (depending on the visual task) are indicated, while in the 'background area' a minimum value of 0.1 is prescribed. An algorithm for defining the spacing and number of nodes of the calculation grid is provided, but it is not specified neither how $U_{O}$ is defined (whether $E_{\min } / E_{\text {average }}$ or $E_{\min } / E_{\max }$ ) nor from which considerations these values are obtained. Slater and Boyce [90] argued that it might not be appropriate for interiors lit by side windows since they tend to show non-uniform light distributions, which can distort values of $U_{O}$. In EN 12464-1, these uniformity ratios have been recommended for artificial lighting or roof lights. The same standard states that in case of lighting from windows "the additional benefits of daylight can compensate for the lack of uniformity" [77] though the entity of such 'compensation' is not quantified.

\subsection{Indices for assessing glare}

Glare is a complex phenomenon and several approaches characterized by different complexity in the calculation have been used for assessing it or for predicting potential discomfort events. The direct approach consists in measuring or calculating the luminance of a given light source seen by a given observation point. A more elaborated approach relates the glare risk to the luminance contrast of objects present in the visual field of an observer. Other glare indices are based on equations that relate some key factors to subjective judgments of the degree of discomfort experienced in indoor 
environments [18]. In essence, such indices consider the contrast between the luminance of the glare source, the source angular size seen from the observer and the background luminance as seen from the position of the observer. These factors are generally combined in the following way [97]:

$$
G=\left(\frac{L_{s}^{e} \cdot \omega_{s}^{\prime}}{L_{b}^{g} \cdot f(P)}\right),
$$

where $L_{s}$ is the luminance of the glare source (i.e., the maximum luminance as observed from the user's viewpoint); $L_{b}$ is the background luminance (i.e., the average luminance in the field of view with the glare source removed); $\omega_{s}$ is the solid angle subtended by the source with respect to the observer's eye; $P$ is the position index, accounts for the location of the glare source in the field of view; the exponents (here named $e, f$ and $g$ ) give a suitable weighting to each of the various factors and vary according to the specific glare formulae. Several metrics fit the basic structure of this equation: British Glare Index (BGI), Daylight Glare Index (DGI), CIE Glare Index (CGI), CIE Unified Glare Index (UGR). In general, according to this model: (i) larger and brighter sources increase the glare risk, (ii) a brighter background luminance decreases the glare risk, (iii) the more a glare source is far from the center of the visual field, the lower is the risk of disturbing the observer [98].

More recently this approach has been complemented combining a modified glare index formula with the vertical eye illuminance evaluated in the same point, showing a stronger correlation with user's response regarding glare perception [20]. In fact, in exceedingly bright scenes, discomfort can be predicted even without significant visual contrast [98].

\subsubsection{Luminance}

Luminance seen in a given point of a surface along a given direction is a physical quantity that measures the luminous intensity emitted in such direction per unit of the visible area around the given point,

$$
L_{\gamma}=\frac{d I_{\gamma}}{d A_{\text {visible }}} \quad\left[\text { nit or } c d / \mathrm{m}^{2}\right],
$$

where $\gamma$ is the angle comprised between the normal to the emitting surface and the line joining the emission point and the observation point.

According to Suk, Schiler [99], the identification of the acceptable absolute luminance value of glare sources (as contrasted to the ratio of luminance of the source relative to the background) is the most critical issue when attempting to define an upper limit value of the glare factor for a particular glare scene. Moreover, there is no general agreement on such upper limit values. Maximum thresholds for luminance of the source of 2000 nit in any point and between 500 and 2000 nit for peripheral view are proposed in [91], and can be doubled if the glare source is natural light. Wienold and Christoffersen [20] proposed 2000, 4000 and 6000 nit as thresholds for 'acceptable', 'just uncomfortable' and ‘intolerable glare’ respectively. Similarly, Shin, Yun [100] proposes 3 200, 5600 and 10000 nit respectively for the same three categories. Even greater values were proposed in [101]. In the end, given the wide variability of these thresholds, in order to directly use absolute luminance values to evaluate glare, further investigation is required to ascertain how the correlation between luminance and glare perception by observers were obtained [99]. 


\subsubsection{Luminance ratio}

The occurrence of glare depends not only on absolute luminance values, but also on relative luminance values and contrast, usually expressed by luminance ratios. The concept at the base of the development of the luminance ratio is that the luminance in the visual field of an observer doing a static task has to remain in reasonable ratios for preventing glare caused by a heavy contrast. In order to use this index, the visual field has to be subdivided in zones. Osterhaus [102] identified three zones (the central zone, where the visual task takes place; the adjacent zone delimited by a cone of $60^{\circ}$; and the non-adjacent zone, delimited by a wider cone of $120^{\circ}$ ) characterized by luminance ratios of 1:3:10. By the way, other authors $[97,103]$ showed that, in real life conditions, occupants can tolerate even of 1:40 and up to 1:100 between the central zone and the surroundings. Later more detailed values were provided in [104]: 1:3 for the visual task and immediate surroundings, 1:10 for the visual task and near surfaces, 1:20 for the visual task and more distant surfaces, and 1:40 for the visual task and any other surfaces in the field of view. The nature of the light source influences perception since, for example, people typically tolerate, when sitting next to a window, a high amount of daylight, rather than pulling the blinds down and switching on artificial lighting. In addition, the relative position of the light source and the occupant plays an important role. Therefore, the ratios themselves should vary depending on the room layout and luminance distribution [97]. Again, threshold values of contrast ratio vary, and it is difficult to determine which value should be used: according to Suk, Schiler [99], further investigation is required to ascertain whether luminance ratios alone can provide sufficient information to detect potential glare issues.

\subsubsection{British Glare Index}

British Glare Index (BGI) is derived from the glare equation empirically developed by Petherbridge and Hopkinson [53] at the Building Research Station (BRS):

$$
\begin{gathered}
B G I=10 \log _{10}\left[0.478 \sum_{i=1}^{n}\left(\frac{L_{s, i}^{1.6} \cdot \omega_{s, i}^{0.8}}{L_{b} \cdot P_{i}^{1.6}}\right)\right], \\
\text { subject to } \omega_{s} \in(0,0.027] \mathrm{sr}
\end{gathered}
$$

where the subscript $s$ is used for those quantities depending on the observer position and $i$ for those quantities depending on the light sources, $\omega_{\mathrm{s}}$ is the solid angle subtending the source $i$ from the position of the observer, $P$ is the Guth position index, expressing the dependence of perceived discomfort glare on the position of the source $i$ with respect to the observer, $L_{s i}$ is the luminance in the direction connecting the observer with each source, and $L_{b}$ is the background luminance that, for windows, is the average luminance of the wall excluding the window. The Guth position index was first presented as a chart, and later was converted into an equation [17] to make it easier to use. BGI was developed for small light sources and this suggests being more suitable with artificial light sources than with large sources like windows. Basically, BGI is defined on a three-unit step scale where a value of 10 indicates 'imperceptible glare' and a value of 28 indicates 'just intolerable' [18, 61, 105]. Boyce [106] suggested a further degree corresponding to 30 units indicating an 'intolerable glare’.

$B G I$ is a short-term, local and one-tailed glare index, with the following limitations: (i) it does not accurately predict glare from large sources, as it can only evaluate small sources seen within solid angles lower than 0.027 sr [61], (ii) compared 
to other glare indices (such as DGI and CGI, which are described later) BGI is the least accurate when using a wide light source [107] and (iii) it does not take into account the effect of adaptation.

\subsubsection{Visual Comfort Probability}

Visual Comfort Probability (VCP) was introduced by Guth [55] to evaluate discomfort glare and later modified to be applied to all type of lighting systems [108]. This index aims at evaluating the percentage of the population of observers who would consider comfortable a given luminous environment produced by a lighting system for performing a task.

The acceptability criterion is the perception of glare caused by direct light from light sources and the comfort threshold is the so-called Borderline between Comfort and Discomfort (BCD) [109]

$$
B C D=185.67 L_{v f}^{0.44}\left(\omega_{s, i}^{-0.21}-1.28\right),
$$

where $\omega_{\mathrm{s}, \mathrm{i}}$ is the solid angle subtended by luminaires from observer's position, in sr, and $L_{v f}$ is the average luminance of the visual field, assuming that the amplitude of the entire field of view is $5 \mathrm{sr}$, in $\mathrm{cd} / \mathrm{m}^{2}$

$$
L_{v f}=\frac{L_{w} \cdot \omega_{w}+L_{f c} \cdot \omega_{f}+L_{c c} \cdot\left(\omega_{c}-\sum_{i-1}^{n} \omega_{s, i}\right)+\sum_{i-1}^{n}\left(L_{s, i} \cdot \omega_{s, i}\right)}{5},
$$

where $L_{w}$ is the wall luminance, $\omega_{\mathrm{w}}$ is the solid angle subtended by walls, $L_{f c}$ is the floor cavity luminance, $\omega_{\mathrm{f}}$ is the solid angle subtended by the floor, $L_{c c}$ is the ceiling cavity luminance, $\omega_{\mathrm{c}}$ is the solid angle subtended by ceiling, The procedure to compute VCP requires to calculate, at first, the Glare-sensation index, $M$, for every glare source $i$

$$
\begin{gathered}
M=\frac{0.5 L_{s, i}}{P \cdot L_{y f}^{0.44}}\left(20.4 \omega_{s, i}+1.52 \omega_{s, i}^{0.2}-0.075\right), \\
\text { subject to } \omega_{s, i} \geq 0.0000002924 s r
\end{gathered}
$$

where $L_{s, i}$ is the luminance of a glare source evaluated in the direction of observer's eyes, and $P$ is the Guth position index. This equation is constrained in order to avoid the Glare-sensation index assumes a negative value. Then, the Discomfort Glare Rating (DGR) can be calculated for all $n$ glare sources within the visual field

$$
D G R=\left(\sum_{i=1}^{n} M_{j}\right)^{n+(i 09)+}
$$

Therefore, VCP can be computed with the integral equation

$$
V C P=\frac{100}{\sqrt{2 \pi}} \int_{-\infty}^{6.3741 .3227 \ln (D C R)} e^{-r^{2} / 2} d t,
$$

or according to a numerical approximation proposed by IESNA [17]

$$
\begin{gathered}
V C P=279-110\left(\log _{10} D G R\right)+C \\
\text { with }\left\{\begin{array}{ll}
C=0 & \text { if } 55 \leq D G R \leq 200 \\
C=350\left(\log _{10} D G R-2.08\right) & \text { if } D G R<55 \wedge D G R>200
\end{array} .\right.
\end{gathered}
$$

VCP is a short-term, local and one-tailed glare index. It is also accompanied by threshold values and an assessment scale defined from 0 to 100 (Table 5). 
Basically, IES [110] suggests that an artificial lighting source does not cause discomfort glare if three conditions are contemporary satisfied:

- $\quad$ The VCP value is strictly higher that 70 ,

- The luminance ratio between the luminance of the brightest $6.5 \mathrm{~cm}^{2}$ area and the average luminaire luminance value does not exceed $5: 1$ at $45^{\circ}, 55^{\circ}, 65^{\circ}, 75^{\circ}$ and $85^{\circ}$ calculated from the nadir for both transversal and longitudinal visions,

- Maximum luminance values of the lighting sources viewed both transversally and longitudinally do not have to exceed the thresholds reported in table 4.

Table 4: Maximum acceptable luminance values of the lighting sources, transversally and longitudinally viewed.

\begin{tabular}{ll}
\hline Angle from the nadir $\left(^{\circ}\right)$ & Maximum luminance (nit) \\
\hline $85^{\circ}$ & 1695 \\
$75^{\circ}$ & 2570 \\
$65^{\circ}$ & 3860 \\
$55^{\circ}$ & 5500 \\
$45^{\circ}$ & 7710 \\
\hline
\end{tabular}

$V C P$ was developed just for assessing typically-sized, ceiling-mounted luminaires with a uniform luminance. Therefore, it is not recommended for use with non-uniform or very large or very small light sources, such as compact luminaires as halogens, or for evaluating glare due to daylight [111]. Moreover, since it is an empirical relationship derived from data collected during a variety of experiments, IESNA [17] suggests that differences in the VCP values of two lighting systems are not significant if they are not higher than 5 units.

\subsubsection{CIE Glare Index}

In order to correct the mathematical inconsistency of the BGI for multiple glare sources, Einhorn [60] presented a new index, later accepted by CIE, and thus named CIE Glare Index (CGI)

$$
C G I=8 \log _{10}\left[2 \frac{1+\left(E_{d} / 500\right)}{E_{d}+E_{i}} \sum_{i=1}^{n}\left(\frac{L_{s, i}^{2} \cdot \omega_{s, i}}{P_{i}^{2}}\right)\right] .
$$

To compute CGI, illuminances due to both direct $\left(E_{d}\right)$ and diffuse light $\left(E_{i}\right)$ evaluated on the horizontal plane passing through observer's eyes are required. This index ranges with a three-unit step between 10, meaning that glare is 'imperceptible', to 34, meaning that glare is 'intolerable'; Cai and Chung [112] suggest 19 as a typical border value between comfort and discomfort glare (table 5); instead, according to Jakubiec and Reinhart [113], CGI lower than 13 means that glare is imperceptible and CGI higher than 28, means that glare is intolerable.

CGI is a short-term, local and one-tailed glare index. It is also accompanied by threshold values. 


\subsubsection{Discomfort Glare Index}

Discomfort Glare Index (DGI) derives from the CGI and aims at predicting glare from large sources, such as a window, described by its luminance $L_{\text {win. }}$ In [37], later modified in [61], it is defined as follows:

$$
D G I=10 \log _{10}\left[0.478 \sum_{i=1}^{n}\left(\frac{L_{s, 1}^{1.6} \cdot \omega_{s, t}^{0.8}}{L_{b}+0.07 \omega^{0.5} \cdot L_{\text {win }} \cdot P_{i}^{1.6}}\right)\right],
$$

where $\omega$ is the solid angle subtending each source from the point of view of the observer, modified with respect to field of view and Guth position index of each luminaire (i). DGI values are associated with several levels of discomfort glare. A value of DGI equal to 22 is considered a reasonable acceptability threshold [61, 80]. DGI is a short-term, local, onetailed index which, according to several authors, has some noticeable limitations: (i) it refers only to uniform light sources: this excludes direct sunlight and does not consider that non-uniform sources can cause more glare when positioned perpendicularly to the line of view and less glare when located between $10^{\circ}$ and $20^{\circ}$ from the line of view, as pointed out by [114]; (ii) DGI is not reliable when the source fills almost the whole field of view and when the background luminance equals the source luminance [27]; (iii) a few differences between the value predicted by DGI and the evaluation in real sky conditions were determined in [27, 115].

\subsubsection{New Discomfort Glare Index}

A modified index called $D G I_{N}$ was proposed by Nazzal [21] aiming at overcoming some of the limitations of the standard DGI. The components of the equation are similar to the ones used for DGI, but their definition is different. Sources of luminance and solid angles are modified to include the effect of observer's position.

$$
D G I_{N}=8 \log _{10}\left\{0.25 \frac{\sum_{i=1}^{n} L_{\text {exterior },}^{2} \cdot \Omega_{p N}}{L_{\text {uduptution }}+0.07\left[\sum_{i-1}^{n}\left(\omega_{N, i} \cdot L_{\text {winden }, i}^{2}\right)\right]}\right\} \text {, }
$$

where $\omega_{N}$ is the apparent solid angle of each source seen from the point of observation and $\Omega_{p N}$ is the corrected solid angle subtended by the source, $L_{\text {window }}$ is the average vertical luminance $\left[\mathrm{cd} / \mathrm{m}^{2}\right]$ of the window surface; $L_{\text {adaptation }}$ is the average vertical luminance $\left[\mathrm{cd} / \mathrm{m}^{2}\right]$ of the surroundings; $L_{\text {exterior }}$ is the average vertical unshielded luminance $\left[\mathrm{cd} / \mathrm{m}^{2}\right]$ of the outdoors due to the direct light from the sun, diffuse light from the sky and reflected light from the ground and other external surfaces. $L_{\text {adaptation }}$ replaces background luminance $\left(L_{B}\right)$ and takes into account the greater influence that the surrounding luminance has on the discomfort glare [21].

\subsubsection{Unified Glare Rating}

CIE's Unified Glare Rating (UGR) is defined in [66] and reported in [97]:

$$
\begin{aligned}
& U G R=8 \log _{10}\left[\frac{0.25}{L_{h}} \sum_{i=1}^{n}\left(\frac{L_{s, i}^{2} \cdot \omega_{s, i}}{P_{i}^{2}}\right)\right] . \\
& \text { subject to } \omega_{s} \in\left[3 \cdot 10^{-4}, 10^{-1}\right] \mathrm{sr}
\end{aligned}
$$


In EN 12464-1, a series of reference values are provided for a number of different tasks and activities. UGR ranges between 10 (imperceptible) to 34 (intolerable) with a three-unit step; like CGI, a value of 19 is typically considered the frontier between comfort and discomfort glare [112]. EN 12464-1 reports UGR limit values for a number of visual tasks. This short-term, local, one-tailed index has some limitations. UGR only deals well with very small glare sources with a solid angle included in the range $\left[3 \cdot 10^{-4}, 10^{-1}\right]$ sr. Thus, UGR is suitable to assess glare due to artificial light sources rather than to large-area sources like windows or curtain walls. Moreover, since the position index applies for directions that are above the observer's line of sight, this index could not be suitable for predicting glare in those layouts where the glare sources are positioned below the observer's line of sight. For large light sources such as luminaires with an area greater than $1.5 \mathrm{~m}^{2}$, CIE recommends an extended version of UGR called Great-room Glare Rating (GGR)

$$
\begin{gathered}
G G R=U G R+8\left(1.18-0.18 \frac{A_{1}}{A_{0}}\right) \log _{10}\left[\frac{2.55\left(1+\frac{E_{d}}{220}\right)}{1+\frac{E_{d}}{E_{i}}}\right], \\
\text { subject to } A_{0}>1.5 m^{2}
\end{gathered}
$$

where $A_{0}$ is the projected area of the glare source towards the nadir and $A_{1}$ is the room floor area divided by the number of glare sources [68]. Moreover, UGR cannot be used for light sources smaller than $3 \cdot 10^{-4} \mathrm{sr}$, since UGR tends to overestimate glare caused by those very small electric light sources [112], therefore CIE proposed a modified version of $U G R$ called $U G R_{\text {small }}$ to be used with small light sources with a projected area $\left(A_{0}\right)$ lower than $0.005 \mathrm{~m}^{2}$ [68]

$$
\begin{gathered}
U G R_{\text {small }}=8 \log _{10}\left[\frac{0.25}{L_{b}} \sum_{i=1}^{n}\left(200 \frac{I_{i}^{2}}{r_{i}^{2} \cdot P_{i}^{2}}\right)\right], \\
\text { subject to } A_{0}<0.005 \mathrm{~m}^{2}
\end{gathered}
$$

where $I_{i}$ is the luminous intensity of the light source causing glare in the direction of observer's eyes and $r_{i}$ is the distance between that light source and observer's eyes. Although $U G R, G G R$ and $U G R_{\text {small }}$ shall be used in different cases, they have been designed to provide the same level of discomfort glare.

\subsubsection{Discomfort Glare Probability}

Discomfort Glare Probability (DGP) is a short-term, local, one-tailed index assessing glare, which was introduced in [69] and validated in [20]. Its formulation is:

$$
D G P=5.87 \cdot 10{ }^{5} E_{v}+0.0918 \cdot \log _{10}\left[1+\sum_{i=1}^{n}\left(\frac{L_{s, i}^{2} \cdot \omega_{s, i}}{E_{v}^{1.87} \cdot P_{i}^{2}}\right)\right]+0.16,
$$

where $E_{v}$ is the vertical eye illuminance, produced by the light source [lx]; $L_{S}$ the luminance of the source [cd/m²]; $\omega_{S}$ the solid angle of the source seen by an observer; $P$ is the position index, which expresses the change in experienced discomfort glare relative to the angular displacement of the source (azimuth and elevation) from the observer's line of sight. The equation is valid within the range of $D G P$ between 0.2 and 0.8 , and for vertical eye illuminance $\left(E_{v}\right)$ above $380 \mathrm{~lx}$. 
The glare indices previously analyzed just focus on the contrast ratio between the background average luminance and the glare source luminance [99], DGP instead includes also an evaluation of the level of illuminance perceived by the observer by means of the term $E_{v}$. For this reason, $D G P$ shows a stronger correlation with the user's response regarding glare perception [69]. Thus, according to Suk, Schiler [99], it would be the most appropriate metric to analyze absolute glare issues. However, a limitation of procedure is that it usually involves a lot more computation time and user effort compared to the simple analytic calculations required by most of the other glare indices [16]. First, designer must choose one or more viewpoints of interest, basically corresponding to key occupant positions in the space, then, renderings in the RADIANCE picture format have to be produced, and finally a glare evaluation has to be carried out using evalglare, a specifically developed software able to detect glare sources on a $180^{\circ}$ fish-eye scene [69].

\subsubsection{Wienold et al.’s simplification of Discomfort Glare Probability}

Wienold, Jiang [33] propose a simplified version of DGP (DGPs) where the logarithmic term depending on the local quantities (luminance and solid angle of the source seen from the observation point) is neglected

$$
\left.D G P s\right|_{\text {Wienteld }}=6.22 \cdot 10^{-5} \cdot E_{V}+0.184 \text {. }
$$

This simplification significantly reduces the computational effort of calculating the index and is justified since, "the correlation between the linear function of vertical eye illuminance and the probability of disturbed persons was stronger than all other tested functions" [20]. The DGPs approach is meant to overcome the high effort required to generate images at every time step of the simulations by neglecting the influence of peak glare sources [35]. Basically, they cannot be used for absolute glare factor conditions that include a direct view of glare sources in the field of view of the observer [99].

\subsubsection{Hviid et al.’s simplification of Discomfort Glare Probability}

Hviid, Nielsen [34] also proposed to neglect the dependence of DGP on the aforementioned local quantities, so that they introduced another simplified DGP (DGPs) that just uses and depends linearly on the vertical illuminance at eye level.

$$
\left.D G P S\right|_{H v i d}=5.87 \cdot 10^{-5} \cdot E_{\mathrm{Y}}+0.16 \text {. }
$$

It is very similar to Wienold's version of DGPs, and for the same value of $E_{V}$, Hviid's version of $D G P_{s}$ predicts a glare probability $2 \div 3 \%$ lower than Wienold's version. Similar to Wienold's DGPs, this simplified index can be used only if no direct sun, or specular reflection of it, hits observer's eyes.

\subsubsection{Enhanced Simplified Discomfort Glare Probability}

Simplified $D G P$-based indices have been proposed aiming at shortening simulation times in respect to standard $D G P$, but they cannot be used in case of direct sun transmission into a room. The Enhanced Simplified DGP (eDGPs) is proposed and validated against two full-year hourly datasets by Wienold [35] in order to keep at the same time a certain degree of simplicity in respect to standard DGP in situations where direct sun transmission into a room cannot be neglected. The governing equation is similar to the traditional DGP in Eq. (21). 


$$
e D G P s=\underbrace{c_{1} \cdot E_{v}}_{\text {Term } 1}+\underbrace{c_{2} \cdot \log _{10}\left[1+\sum_{i=1}^{n}\left(\frac{L_{s, i}^{2} \cdot \omega_{s, i}}{E_{v}^{1.87} \cdot P_{i}^{2}}\right)\right]}_{\text {Ten1 } 2}+c_{3} \cdot
$$

Term 1 depends on the vertical eye illuminance, and Term 2 depending on the local quantities is computed by using a simplified image that just includes the main glare sources, not calculating the exact luminance distribution. A significant time reduction is obtained by neglecting the indirect ambient reflections, however, leading to reasonable results in most cases if compared to DGP [35].

\subsubsection{Predicted Glare Sensation Vote}

Predicted Glare Sensation Vote (PGSV) is based on experiments over 200 participants, exposed to 120 different test conditions with simulated windows with uniform luminance $[36,116]$. Its formulation is

$$
\begin{gathered}
P G S V=3.2 \log _{10} L_{1 w p}-0.64 \log _{10} \omega_{s}+\left(0.79 \log _{10} \omega_{s}-0.61\right) \log _{10} L_{b}-8.2 \\
\text { with } L_{b}=\left(\frac{E_{v} / \pi-L_{n p} \Phi_{w}}{1-\Phi_{w}}\right) \\
\text { subject to } \omega_{s} \in(0,0.021]_{s r}
\end{gathered}
$$

where $E_{V}$ is the vertical eye illuminance [lx], $L_{w p}$ is the average luminance visible within the window plane [cd/m²], $\omega_{\square}$ is the solid angle of the source $[\mathrm{sr}], \Phi_{W}$ is a configuration factor of the window.

The use of an average luminance for the entire window has limitations to be used in actual conditions since there can be a big difference in terms of luminance between the sky and the ground seen through the window. Moreover, according to this formulation, the luminance of the glare source has more impact on the discomfort glare than the size of source, and "this could under-evaluate the level of discomfort glare" [24].

\subsubsection{J-Index}

J-Index is presented in $[65,117]$ to define the effects of non-optimal light conditions, i.e., insufficient or excessive luminance and non adapted contrast. The subjective evaluation of the discomfort glare refers to scale models in which the subjective evaluation is compared with those obtained in full-scale environments [27]. In particular, the J-Index expresses the difference between the maximum possible visual acuity $\left(A_{\max }\right)$ and the visual acuity that a person would reach $(A)$ in a given light condition:

$$
\begin{gathered}
J=\frac{\left(A_{\max }-A\right)}{A_{\max }} \\
\text { with } A=A_{\max } \cdot \tilde{r}_{1}\left(C_{1}\right) \cdot \tilde{r}_{2}\left(C_{2}\right) \cdot \tilde{r}_{3}\left(E_{P}\right)
\end{gathered}
$$

where $C_{1}$ is the contrast between the target and the background, $C_{2}$ is the contrast between the background and its surroundings, $E_{p}$ is the pupil illuminance and $\tilde{r}_{1}, \tilde{F}_{2}$ and $\tilde{F}_{3}$ are the relative influences of $C_{1}, C_{2}$ and $E_{p}$ on the acuity. 


\subsubsection{Comparison of glare sensation scales}

x presents the comparison of five discomfort glare indices as arranged in [27] and [112] on a nine-point glare sensation scale. Cai and Chung [112] modified some numerical values to meet the semantic descriptions with the discomfort glare scale resolution; e.g., regarding BGI, the intolerable glare degree is shifted from 30 to 31 to match the three-unit steps of BGI.

Table 5: Comparison of a number of glare discomfort indices on a nine-point glare sensation scale. Source: [27, 112].

\begin{tabular}{|c|c|c|c|c|c|}
\hline Degree of glare sensation & BGI & $V C P$ & CGI & DGI & UGR \\
\hline Intolerable & 31 & 12 & 34 & 30 & 34 \\
\hline Just intolerable & 28 & 20 & 31 & 28 & 31 \\
\hline Uncomfortable & 25 & 28 & 28 & 26 & 28 \\
\hline Just uncomfortable & 22 & 36 & 25 & 24 & 25 \\
\hline Unacceptable & 19 & 43 & 22 & 22 & 22 \\
\hline Just acceptable & 16 & 50 & 19 & 20 & 19 \\
\hline Perceptible & 13 & 59 & 16 & 18 & 16 \\
\hline Just perceptible & 10 & 67 & 13 & 16 & 13 \\
\hline Imperceptible & 7 & 75 & 10 & 14 & 10 \\
\hline
\end{tabular}

Jakubiec and Reinhart [113] instead propose a different comparison matrix based on a four-point glare sensation scale (Table 6).

Table 6: Comparison of a number of glare discomfort indices on a four-point glare sensation scale. Source: [113]

\begin{tabular}{llllll}
\hline Degree of glare sensation & $\boldsymbol{V C P}$ & $\boldsymbol{C G I}$ & $\boldsymbol{D G I}$ & $\boldsymbol{U G R}$ & DGP \\
\hline Intolerable & $<40$ & $>28$ & $>31$ & $>28$ & $>0.45$ \\
Disturbing & $40 \div 60$ & $22 \div-28$ & $24 \div 31$ & $22 \div-28$ & $0.35 \div 0.4$ \\
Perceptible & $60 \div 80$ & $13 \div 22$ & $18 \div 24$ & $13 \div 22$ & $0.3 \div 0.35$ \\
Imperceptible & $>80$ & $<13$ & $<18$ & $<13$ & $<0.3$ \\
\hline
\end{tabular}

\subsection{Indices for assessing the quality of light}

The issue of assessing the quality of light generated by an artificial light source is quite old, but still appears to be in a developing phase. In 1948, CIE started developing a metric, called Color Rendering Index (acronym CRI or $R_{a}$ ), in order to evaluate artificial light sources. In 1965, the first version was released and, in 1974, was modified to take into account the psychophysiological effects of chromatic adaptation through the von Kries chromatic adaptation transform [118]. Several other indices were developed over time, most of them aiming at improving the Color rendering index, which is subject to a number of deficiencies [119]. In 1967 Judd [56] proposed the Flattery index. In 1972 Thornton [57] introduced 
the Color Discrimination Index and, in 1974, the Color Preference Index [58]. Between 1983 and 1993, Xu proposed and developed the Color Rendering Capacity [62, 120, 121]. In 1986, Pointer developed a new color rendering index [63] that was ameliorated in 2004 [122]. In 2000, Hashimoto, Yano [67] proposed the Feeling of Contrast Index. In 2010, Davis and Ohno [71] developed the Color Quality Scale.

In 2007, the CIE Technical Committee 1-62 ‘Colour rendering of White LED Light Sources’ acknowledged that the CRI fails in predicting the color rendering performance of LED and recommended developing a new metric for assessing white-light sources for illumination [123]. To this aim, in 2008, CIE established the Technical Committee 1-69 entitled 'Colour Rendition by White Light Sources'. It was meant “to investigate new methods for assessing the colour rendition properties of white-light sources used for illumination, including solid-state light sources, with the goal of recommending new assessment procedures” [124], however, an agreement on a metric that would have replaced CRI was not achieved. Then, in 2012, CIE established two new the Technical Committee (TC): TC 1-90 entitled ‘Colour Fidelity Index’ and TC 1-91 entitled 'New Methods for Evaluating the Colour Quality of White-Light Sources'. TC 1-90 aimed “To evaluate available indices based on colour fidelity for assessing the colour quality of white-light sources with a goal of recommending a single colour fidelity index for industrial use” [124]. TC 1-91 aimed “To evaluate available new methods for evaluating the colour quality of white-light sources with a goal of recommending methods for industrial use. (Methods based on colour fidelity shall not be included)” [124]. The activities of TC 1-90 and TC 1-91 are still in progress.

For comprehensive reviews about color rendering metrics, the reader may refer to [75, 125].

\subsubsection{CIE Color Rendering Index}

CIE Color Rendering Index (acronym $C R I$ or $R_{\mathrm{a}}$ ) is the result of a long development. It was first proposed by Nickerson and Jerome [126], then published by CIE in 1974 [118] and lastly modified in 1995 [127]. The aim of CRI is to assess the color rendering that is defined as the "effect of an illuminant on the color appearance of objects by conscious or subconscious comparison with their color appearance under a reference illuminant” [64]. Therefore, it is a quantitative evaluation of the capability of a light source to render faithfully the colors of various objects with respect to a reference light source. CRI is based on chromaticity shifts of eight standard color samples illuminated by a test and a reference light sources [127]. The reference source is a blackbody Planckian radiator for test sources with a Correlated color temperature ${ }^{1}$ (CCT) [127] lower than $5000 \mathrm{~K}$; otherwise it is a CIE Daylight illuminant matched to the CCT of the test source.

The chromaticity coordinates of each of the eight-CIE test samples under the reference illuminant and the test source are expressed on the 1960-CIE color space and are adapted using the von Kries chromatic adaptation transform. Then, the Euclidean distance between every pair of chromaticity coordinates corresponding to each of the eight-CIE test samples, $\Delta E_{i}$, are computed, and the so-called Special CRIs, $R_{i}$, are calculated per every pair of chromaticity coordinates.

$$
R_{i}=100-4.6 \Delta E_{i}
$$

${ }^{1}$ The Correlated color temperature is "the temperature of the Planckian radiator whose perceived color most closely resembles that of a given stimulus at the same brightness and under specified viewing conditions” $128 . \quad$ CIE/IEC, International Lighting Vocabulary, in CIE/IEC 17.4 1987, International Commission on Illumination and International Electrotechnical Commission. 
Finally, the arithmetical mean of all $R_{i}$ provides the $C R I$.

$$
C R I=R_{a}=\frac{1}{8} \sum_{i=1}^{8} R_{i} \in[0,100] .
$$

CRI ranges from 0 to 100 . A CRI of 100 specifies the best possible faithfulness to a reference. Basically, a source with $C R I$ not lower than 90 is considered excellent, $C R I$ in the range $80 \div 89$ is considered good, and values of $C R I$ comprised within the range $70 \div 79$ are considered acceptable [129]. Table 7 reports typical values of the luminous efficacy, CCT and $C R I$ for common lighting sources.

Table 7: Typical values of the luminous efficacy, Correlate color temperature and Color Rendering Index for commonly used light sources

\begin{tabular}{|c|c|c|c|c|}
\hline Light source & $\begin{array}{l}\text { Luminous efficacy } \\
(\mathrm{lm} / \mathrm{W})\end{array}$ & $\begin{array}{l}C C T \\
(\mathrm{~K})\end{array}$ & CRI value & Source \\
\hline Incandescent/halogen & $5 \div 27$ & $2700 \div 3200$ & 100 & [130] \\
\hline Fluorescent & $60 \div 105$ & $2700,3000,4000,6500$ & $60 \div 95$ & [130] \\
\hline \multirow[t]{5}{*}{ Light-emitting diode (LED) } & $<50$ & $3000 \div 8000$ & $<90$ & [130] \\
\hline & 324 & $3000 \div 7000$ & 99 & [131] \\
\hline & 332 & & 98 & \\
\hline & 366 & & 85 & \\
\hline & 430 & & 3 & \\
\hline Ceramic metal halide & $68 \div 95$ & $3000 \div 4200$ & $80 \div 95$ & [130] \\
\hline \multirow[t]{2}{*}{ Standard metal halide } & $50 \div 100$ & $3000 \div 6000$ & $70 \div 90$ & [131] \\
\hline & $75 \div 140$ & $3000,4000,5600$ & $65 \div 95$ & [130] \\
\hline Compact fluorescent & $50 \div 85$ & $2700,3000,4000,6500$ & 80 & [130] \\
\hline Induction lamp & $60 \div 80$ & $2700 \div 4000$ & 80 & [131] \\
\hline \multirow[t]{2}{*}{ High-pressure mercury } & $40 \div 60$ & 4000 & $40 \div 60$ & [131] \\
\hline & $35 \div 60$ & $3400,4000,4200$ & $40 \div 60$ & [130] \\
\hline White high-pressure sodium & & 2700 & $>80$ & [131] \\
\hline $\begin{array}{l}\text { Color improved high-pressure } \\
\text { sodium }\end{array}$ & & 2200 & $\sim 65$ & [131] \\
\hline \multirow[t]{2}{*}{ Standard high pressure sodium } & $80 \div 100$ & 2000 & $\sim 20$ & [131] \\
\hline & $50 \div 130$ & $2000,2200,2500$ & $10 \div 80$ & [130] \\
\hline
\end{tabular}

CRI was primarily designed to evaluate fluorescent lamps by aiming to measure the naturalness of objects' colors, but it has not been substantially modified in the last 40 years [132].

This index has some limitations: (i) CRI measures the faithfulness of an illuminant to an ideal light source with the same CCT, but such ideal source may distort colors' appearance if it has an extreme color temperature [132]; (ii) since two light 
references -chosen depending on CCT values- are used, CRI results to have a discontinuity at $5000 \mathrm{~K}$; (iii) the 1960CIE color space is non uniform and poorly performs when used to calculate the color rendering performance of an illuminant [132]; (iv) the von Kries chromatic adaptation transform is less performing than other available models [132]; (v) the arithmetical mean does not provide any information on the features of the deviations, i.e., two illuminants can be characterize by a similar value of $C R I$, but can perform much differently if one has some very low value of $R_{i}$; (vi) the mathematical formulation of the $C R I$ allows negative values; (vii) people sometimes can prefer object color to appear different than their appearance under reference illuminants [56, 58], thus challenging the idea of regarding the color rendering of reference illuminants as the standards to which all other sources should be compared; (viii) the eight-CIE test color samples are not very saturated, and this can imply that the color rendering of saturated colors could be poor ever for high values of $C R I$, and this feature of CRI makes it unsuitable to assess LEDs due to their peaked light spectra [123, 132]. Finally, since commercial lamps are improved with regards to some metrics, an unsuitable index could lead to yield wicked illuminants and hinder the development of new products and technologies.

\subsection{2 (General) Color Quality Scale}

To address a number of CRI's flaws, Davis and Ohno [71] developed a new index called (General) Color Quality Scale (CQS ${ }_{a}$ or $Q_{a}$ ) strongly inspired by CRI. Like CRI, CQS $S_{a}$ is a reference-illuminant based metric where the reference light source is matched to the CCT of the test source and delivers a single number output. In order to fix some of the CRI's flaws, $C Q S_{a}$ uses a newer set of test colors constituted by 15 samples, which are more saturated since light sources that perform well on non-saturated colors can be wick on saturated one and, to date, the opposite case has not happened yet. Moreover, it replaces the CIE 1960 uniform color space on which calculating the distance of the chromaticity shifts with either the CIE $L^{*} a^{*} b^{*}$ (CIELAB) and the CIE $L^{*} u^{*} v^{*}$ (CIELUV) color spaces; and the von Kries chromatic adaptation transform is replaced by either the Colour Measurement Committee's chromatic adaptation transform (CMCCAT2000) and the CIE's chromatic adaptation transform (CIE CAT02). The calculation of the CQS ${ }_{a}$ introduces a 'saturation factor' that neglects those chromaticity shifts from the reference illuminant, which are more chromatic since they foster color quality if are not excessive [71]. Furthermore, the arithmetic mean is replaced by the root mean square deviation that amplifies large chromaticity shifts instead of averaging them with others

$$
\Delta E_{\text {RUS }}=\sqrt{\frac{1}{15} \sum_{i=1}^{15} \Delta E_{i}^{2}},
$$

where $\Delta E_{i}$ is the color difference for each color sample illuminated by the test source and the reference illuminant corrected with the saturation factor. Then, the score is computed by an equation similar to the one used in the CRI.

$$
Q_{a, R \text { RAS }}=100-3.1 \Delta E_{\text {RMS }} \text {. }
$$

The scaling factor "3.1" of Eq(34) has been chosen in order to have the General Color Quality Scale value $\left(Q_{a}\right)$ equal to $C R I$ for standard fluorescent lamps and to keep a good degree of consistency between $Q_{a}$ and CRI for traditional illuminants [71]. The formulation to calculate the single value output has been normalized to deliver a percentage value using the equation 


$$
Q_{a, 0100}=10 \cdot \ln \left[\exp \left(\frac{Q_{a, R M S}}{10}\right)+1\right] .
$$

This normalization introduces an arbitrary deformation of the score for values of the index lower than $20 \%$ (that correspond to very poor illuminants, for which a precise assessment is not meaningfully), but has the advantage of avoiding negative values and is characterized by a strong linearity for values of the index higher than $30 \%$. It is hence introduced the 'CCT factor' $\left(M_{C C T}\right)$ that penalizes those illuminant characterized by a CCT lower than $3500 \mathrm{~K}$ since they have a reduced chromatic discrimination performance. Finally, the General Color Quality Scale $\left(Q_{a}\right)$ is given by

$$
Q_{a}=M_{C \mathrm{~T}} \cdot Q_{a, 0-1,0} \cdot
$$

Introducing few modification to this calculation procedure, Davis and Ohno [71] propose other two indices besides $C Q S_{a}$. The former is called Color Fidelity Scale $\left(Q_{f}\right)$ and aims at assessing the faithfulness of object color appearances by neglecting the saturation factor; the latter is called Color Preference Scale $\left(Q_{p}\right)$ and aims "to indicate the overall quality of a light source" [71] by rewarding those light sources that increase the chromaticity of lit objects.

\subsubsection{Flattery Index}

Flattery index $\left(R_{f}\right)$, defined in [56], treats the pattern of chromaticity coordinates of a selected group of objects (not a reference illuminant) as the ideal configuration. It is a reference illuminant based index. The reference illuminant is assigned a $R_{f}$ value of 90 , reserving the value of 100 for a hypothetical 'perfect' illuminant. According to this approach, a 'perfect' illuminant would be the one that accounts for people's preferred hue shifts [133], and that is obtained assigning unequal weights to each of the ten-CIE test colors (table 8).

$$
R_{f}=100-4.6 \overline{\Delta E_{f, k}},
$$

where $\overline{\Delta E_{f, k}}$ is a weighted arithmetic mean of the Euclidean distances between the pairs of the chromaticity coordinates for each of the ten CIE test colors illuminated by the test source and the reference illuminant corrected for by one fifth of the preferred chromaticity shift [56, 134].

Table 8: 10-CIE test colors used in the Flattery Index accompanied by the Munsell notation of each color and the weight assigned to every chromaticity difference.

\begin{tabular}{lll}
\hline CIE test sample index & Munsell notation & Percentage weight \\
\hline 1 & $7.5 \mathrm{R} 6 / 4$ & 5 \\
2 & $5 \mathrm{Y} 6 / 4$ & 15 \\
3 & $5 \mathrm{GY} 6 / 8$ & 5 \\
4 & $2.5 \mathrm{G} 6 / 6$ & 5 \\
5 & $10 \mathrm{BG} 6 / 4$ & 5 \\
6 & $5 \mathrm{~PB} 6 / 8$ & 5 \\
7 & $2.5 \mathrm{P} 6 / 8$ & 5
\end{tabular}




\begin{tabular}{lll}
8 & $10 \mathrm{P} 6 / 8$ & 5 \\
13 & $5 \mathrm{YR} 6 / 4$ & 35 \\
14 & $5 \mathrm{GY} \mathrm{6/4}$ & 15 \\
\hline
\end{tabular}

These modifications with respect to $C R I$ derive from the observed preference for particular characteristics of perceived colors and weights associated to color shifts derive from arbitrary decisions.

Basically, preferred colors tend to be more vivid and saturated [135]; therefore, there is a higher weight to CIE test samples 2, 13 and 14 representing respectively yellow, red and green hues. Then, some hue shifts are preferred, e.g., skin complexion is preferred to appear more saturated and redder than it does under reference illuminants [133, 136] and a bigger weight (35\%) is attributed to the CIE test sample 13; foliage is favored when it appears more saturated and less yellowish [56] and an important weight (15\%) is associated to the CIE test sample 14; instead, the color of butter, which is very important in some lighting environments such as homes, restaurants, stores etc., is preferred to be less saturated and close to the CIE test color 2 [56].

It has to be noticed that, according to [56], the preferred color shifts are supposed to approximate natural overcast skylight, and are intended for illuminants with a CCT greater than $3500 \mathrm{~K}$. This means that people's preferences in the chromaticity-shift magnitude and direction could vary at different color temperatures.

\subsubsection{Color Preference Index}

In 1974, Thornton [58] proposed the Color Preference Index (CPI). It is a reference illuminance based index similar to the $R_{f}$. However, CPI differs from $R_{f}$ since (i) it uses the eight-CIE test color palette, (ii) it assigns equal weight to each of the chromaticity differences between the chromaticity values of the eight samples under the test source and under the reference illuminant evaluated on the 1960-CIE color space, $\overline{\Delta E}$, and (iii) it admits a maximum value of 156 .

$$
C P I=156-7.18 \overline{\Delta E} \text {. }
$$

\subsubsection{Color-Discrimination Index}

In 1972 Thornton [57] proposed the Color-Discrimination Index (CDI) for measuring the capability of a light source in distinguishing objects' colors. This index measures the gamut area computed on a uniform chromaticity diagram, corresponding to a standard set of colors.

Operationally, a light source under investigation is used to illuminate a given sample of given colors. If the spectral power distribution of the light source is known and after choosing a chromaticity diagram, the chromaticity coordinates can be calculated for all sample colors and, then, plotted on the chosen chromaticity diagram. Considering each of these chromaticity coordinates the vertex of a polygon, the enclosed area is called gamut area $(\mathrm{G})$. Its value is used to measure the capacity of the light source to allow "the observer to discriminate among a large variety of object colors simultaneously viewed” [57].

In his paper [57], Thornton uses the 1960-CIE chromaticity diagram, which uses the coordinates $u$ and $v$, and tests his index on the eight test colors adopted for the calculation of CRI. 
One of the advantages of $C D I$ is that the capability of a light source in distinguishing objects' colors does not depend on a reference illuminant and so it provides an absolute measure. Unfortunately, the 1960-CIE chromaticity diagram is not completely uniform with respect to color distribution; hence, a given value of the gamut area does not represent the same separation of the chromaticity points in each part of the diagram. To mitigate this limit, in 1976 CIE introduced the Uniform Chromaticity Scale Diagram (1976-CIE UCS Diagram), which uses the coordinates $u$ ' and $v$ ' and has become the diagram commonly used for gamut area evaluation.

Thornton suggests using the $C D I$ not only for measuring the color-discrimination capability of an illuminant, but also its capability in rendering colors because it performs better than CRI in assessing specified illuminants.

\subsubsection{Feeling of Contrast Index}

A different approach was at the base of the development of the Feeling of Contrast Index (FCI). Hashimoto et al. introduced this index in 1994 [137], then eliminated a complex interpolation procedure and proposed a simplified version of the index in 2007 [138]. FCI estimates the color discrimination (here called 'feeling of contrast' or 'visual clarity') of a light source assuming that saturation is generally preferred in lighting applications [71, 139].

Operationally, FCI is computed by scaling the gamut area of a test light source, $G($ Test), with respect to the gamut area under D65 reference light source, $G(\mathrm{D} 65)$, both assessed for an illuminance level (E) of $1000 \mathrm{~lx}$ produced on a given color sample.

$$
F C l=100\left[\frac{\left.G(\text { Test })\right|_{E-10002 x}}{\left.G(\mathrm{D} 65)\right|_{E-1000 \mathrm{tx}}}\right]^{\frac{3}{2}} .
$$

The two gamut areas are plotted on the CIE LAB color space and calculated for four specifically selected highly saturated colors with red, yellow, green and blue hues, respectively indicated in the Munsell notation with 5R 4/12, 5Y 8.2/10, 5.5G 5/8 and 4.5PB 3.2/6.

This method is intended to be used in conjunction with $C R I$ to comprehensively describe the color-rendering performance of a light source [138].

\subsubsection{Color Rendering Capacity}

The Color Rendering Capacity ( $C R C$ ) quantifies the color rendering potential based on the number of object's colors a light source can render $[62,120]$. This method computes the maximum chromaticity ranges at different luminance level in the CIE 1960 Ultraviolet space, and then plots the areas at the luminance level to form a curve. The relative area under the curve is defined as the color rendering capacity. This method yields the maximum chromaticity range at different relative luminance levels, so CRC actually describes the color rendering properties three-dimensionally [75]. According to the updated method proposed in [121], if all colors rendered by a particular light source are represented in the CIE color space, a solid will form, which volume is used to represent the modified $C R C$ of the illuminant.

\section{Conclusions}


A number of visual comfort indices have been proposed over the time for assessing given characteristics of a luminous environment or the visual perception of humans in such environment. In this paper, the main indices of visual comfort have been collected and reviewed.

Differently from other reviews, this paper deals with all factors of visual comfort such as (i) the amount of light, (ii) the uniformity of light, (iii) the quality of light, and (iv) the rendering quality of light, and not with just one of them. The first outcome of this work consists in providing an overall picture of this topic in order to help researchers and professionals involved in other areas of building performance assessment and building design to understand the complexity and variety of visual comfort and give him/her a route towards more specialized and detailed documentation.

The main indices of visual comfort are described according to structured categories, and their main features are summarized in table 1 . Therefore, the second outcome of this research consists in providing to designer or analysts a selection tool for helping in choosing the most suitable visual comfort index when dealing with such visual assessment. A third outcome derives from the comparison and analysis of collected indices. A few outcomes are pointed out in the following:

- Visual comfort is affected by different but coexisting factors. Existent metrics just evaluate one of them at a time; therefore, none of the reviewed indices can be taken a priori as the only parameter to represent a visual environment. Moreover, for the same reason, some metrics have names that can result in misunderstanding for novices e.g., Visual Comfort Probability (VCP) just deals with glare or Frequency of Visual Comfort (FVC) and Intensity of Visual Discomfort (IVD) just assess the amount of light and do not account for the other visual comfort factors.

- In order to compare different buildings or building variants, percentage indices are usually preferable since they do not depend on the absolute magnitude of the involved phenomenon. Moreover, individual values allow easier comparisons and interpretations and more effective usability and readability of the results. For example, illuminance maps can be very useful for evaluating light distribution represented by an illuminance value for every point of a defined space grid; but, if the interest is towards an annual evaluation, the amount of output data increases dramatically, outlining the need of post processing tools in order to maintain an acceptable ease in data interpretation. Thus, indices that are expressed through a single value (or a reduced number of values) as output seem to get along well with long-term simulations and optimization techniques. However, each of those values, e.g., Spatial Daylight Autonomy ( $s D A)$, can be associated to different light situations with different spatial and temporal combinations.

- Among illuminance indices, Useful Daylight Illuminance (UDI) seems to be suitable for long-term and concise evaluation, preserving a great deal of the significant information content of the illuminance time-series. It is twotailed, so it is able to quantify both over-lit and under-lit conditions; it delivers information about useful levels of daylight, and the tendency for excessive levels of daylight that could be associated with glare and excessive solar gain [32]. However, (i) there is no full agreement on illuminance thresholds, (ii) UDI is based on spatial rendering and should be fulfilled in every point of the calculation grid. Hence, this approach provides in output a set of three values for each point of the grid: this can be an obstacle in order to obtain a global and concise 
evaluation of the space. For example, Frequency of Visual Comfort (FVC), a metric that has analogies with UDI, gives just one value as output: illuminance is averaged on the zone of interest since the aim is the definition of a simplified approach to integrate visual and thermal comfort [72]. It has to be noticed that the criterion of the averaging procedure is not explicit; however, this approach seems interesting and would deserve to be further investigated in future works.

- As far as glare is concerned, what emerges is a lack of standardized dependent metrics of glare. There is general agreement on the factors that cause it, but every formula evaluates them differently since there does not seem to be a theoretical common understanding of discomfort glare. Moreover, none of the metrics explicitly consider any correction for possible cultural difference, and neither includes glare source exposure duration as a parameter [74]. However, among the analyzed metrics, Discomfort Glare Probability (DGP) would be the most appropriate to deal with absolute glare issues [99] since (i) it is highly correlated with user's response to glare perception [69], (ii) by including the vertical eye illuminance, it takes account of global brightness of the scene, and not just the contrast between source and background luminance, (iii) unlike other glare indices, it accounts for the observer's dissatisfaction, i.e., expresses the degree of glare in terms of the percentage of observers who consider uncomfortable a given luminous condition.

- It has to be noticed that, in the frame of early design and optimization processes, the evaluation of glare through DGP can result to be difficult to be generalized and successfully adopted, because the use of spatial renderings implicitly requests that the scene is well defined (furniture, materials, observer's point of view), and then the indicator has multiple values for each point of the space and every moment in time. This probably makes $D G P$ not suitable for direct evaluation of glare in multi-objective optimizations: a 'long-term' evaluation of glare could be investigated in the future. To date, however, DGP can be used as a constraint to compare different optimal solutions.

- As far as color rendering is concerned, many metrics have been proposed, but none of them has gained, to date, an international agreement, mainly since good color rendering properties of a light source vary with applications and human personal perception, and it is a matter of conjecture to judge what is better. For these reasons, Guo and Houser [75] advocate the use of multiple measures when making lighting design decisions.

\section{Improvement objectives}

In order to support building designers to devise buildings that explicitly optimize (also) visual comfort of future occupants, the several factors of visual comfort need to be encapsulated in a multi-objective optimization problem. To this aim, reliable metrics have to be firstly identified, improved or developed. These metrics shall be able to summarize in a longterm and global value both an integral of short-term assessments calculated over a given calculation period (e.g., for accounting the dynamic performance of solar shading) and a spatial weighted average of local assessments (e.g., for accounting the dimension and position of windows and skylights). Finally, their calculation has to be integrated into building performance simulation tools. 
Regarding the reviewed indices, future developments might address (i) the definition of agreed rules to summarize the distribution of long-term illuminance-related metrics in a single spatial value, for example, by defining the rules to set a calculation grid and providing appropriate averaging methods, (ii) a reliable and agreed approach to the evaluation of glare, (iii) subsequently the development of a criterion for the long-term evaluation of glare and, finally, (iv) the development of a new index that evaluates a sort of predicted chromatic dissatisfaction of typical occupants of an environment, which is simultaneously illuminated from artificial light sources and daylighting under several usage profiles.

\section{References}

1. Waide, P. and S. Tanishima, Light's Labour's Lost: Policies for Energy Efficient Lighting. 2006, Paris (France): OECD/IEA.

2. Hinnells, M., Technologies to achieve demand reduction and microgeneration in buildings. Energy Policy, 2008. 36(12): p. 4427-4433.

3. Li, D.H.W. and J.C. Lam, An analysis of lighting energy savings and switching frequency for a daylit corridor under various indoor design illuminance levels. Applied Energy, 2003. 76(4): p. 363-378.

4. Li, D.H.W., T.N.T. Lam, and S.L. Wong, Lighting and energy performance for an office using high frequency dimming controls. Energy Conversion and Management, 2006. 47(9-10): p. 1133-1145.

5. Wen, Y.J., J. Granderson, and A.M. Agogino. Towards embedded wireless-networked intelligent daylighting systems for commercial buildings. in Proceedings - IEEE International Conference on Sensor Networks, Ubiquitous, and Trustworthy Computing. 2006.

6. Franzetti, C., G. Fraisse, and G. Achard, Influence of the coupling between daylight and artificial lighting on thermal loads in office buildings. Energy and Buildings, 2004. 36(2): p. 117-126.

7. Jenkins, D. and M. Newborough, An approach for estimating the carbon emissions associated with office lighting with a daylight contribution. Applied Energy, 2007. 84(6): p. 608-622.

8. Krarti, M., P.M. Erickson, and T.C. Hillman, A simplified method to estimate energy savings of artificial lighting use from daylighting. Building and Environment, 2005. 40(6): p. 747-754.

9. Pohl, W. and M. Werner, Lighting, Comfort and Energy and the evaluation of the recommendations of EN 15251. 2010, Intelligent Energy Europe.

10. Linhart, F. and J.L. Scartezzini, Evening office lighting - visual comfort vs. energy efficiency vs. performance? Building and Environment, 2011. 46(5): p. 981-989.

11. Li, D.H.W., et al., An analysis of energy-efficient light fittings and lighting controls. Applied Energy, 2010. 87(2): p. 558-567.

12. USGBC, LEED Reference Guide for Green Building Design and Construction. 2009, Washington DC (USA): US Green Building Council.

13. Philips, Lighting for LEED - Application guide for sustainable offices. 2012, Philips Electronics.

14. Ryckaert, W.R., et al., Criteria for energy efficient lighting in buildings. Energy and Buildings, 2010. 42(3): p. 341347.

15. EN 12665, Light and lighting - Basic terms and criteria for specifying lighting requirements. 2011, European Committee for Standardization: Brussels, Belgium.

16. Andersen, M., et al., An intuitive daylighting performance analysis and optimization approach. Building Research and Information, 2008. 36(6): p. 593-607. 
17. IESNA, The lighting handbook. ninth ed. ed. 2000, New York (USA): Illuminating Engineering Society of North America.

18. Osterhaus, W.K.E., Discomfort glare assessment and prevention for daylight applications in office environments. Solar Energy, 2005. 79(2): p. 140-158.

19. Reinhart, C. and J. Wienold, The daylighting dashboard - A simulation-based design analysis for daylit spaces. Building and Environment, 2011. 46(2): p. 386-396.

20. Wienold, J. and J. Christoffersen, Evaluation methods and development of a new glare prediction model for daylight environments with the use of CCD cameras. Energy and Buildings, 2006. 38(7): p. 743-757.

21. Nazzal, A., A new evaluation method for daylight discomfort glare. International Journal of Industrial Ergonomics, 2005. 35(4): p. 295-306.

22. Hopkinson, R.G., P. Petherbridge, and J. Longmore, Daylight in Architecture 1966, London (UK): William Heineman Ltd.

23. Plympton, P., S. Conway, and K. Epstein, Daylighting in Schools: Improving Student Performance and Health at a Price Schools Can Afford, in American Solar Energy Society Conference. 2000: Madison, Wisconsin (USA). p. 11.

24. Kim, W. and J.T. Kim, The Scope of the glare light source of the window with non-uniform luminance distribution, in SHB2010 - 3rd International Symposium on Sustainable Healthy Buildings. 2010: Seoul (KR).

25. Cantin, F. and M. Dubois, Daylighting metrics based on illuminance, distribution, glare and directivity. Lighting Research \& Technology, 2011. 43(3): p. 291-307.

26. Sapia, C., Daylighting in buildings: Developments of sunlight addressing by optical fiber. Solar Energy, 2013. 89: p. 113-121.

27. Bellia, L., et al., Daylight glare: A review of discomfort indexes, in Visual Quality and Energy Efficiency in Indoor Lighting: Today for Tomorrow 2008: Rome (IT)

28. McColl, S. and J. Veitch, Full-spectrum fluorescent lighting: a review of its effects on physiology and health. Psychological Medicine, 2001. 31(6): p. 949-964.

29. Reinhart, C., J. Mardaljevic, and Z. Rogers, Dynamic daylight performance metrics for sustainable building design. Leukos, 2006. 3(1-4): p. 7-31.

30. Mardaljevic, J., L. Heschong, and E. Lee, Daylight metrics and energy savings. Lighting Research \& Technology, 2009. 41(3): p. 261-283.

31. Carlucci, S. and L. Pagliano, A review of indices for the long-term evaluation of the general thermal comfort conditions in buildings. Energy and Buildings, 2012. 53: p. 194-205.

32. Nabil, A. and J. Mardaljevic, Useful daylight illuminances: A replacement for daylight factors. Energy and Buildings, 2006. 38(7): p. 905-913.

33. Wienold, J., et al., Dynamic simulation of blind control strategies for visual comfort and energy balance analysis, in Building Simulation 2007. 2007: Bejing, China. p. 1197-1204.

34. Hviid, C., T. Nielsen, and S. Svendsen, Simple tool to evaluate the impact of daylight on building energy consumption. Solar Energy, 2008. 82(9): p. 787-798.

35. Wienold, J., Dynamic daylight glare evaluation, in Building Simulation - 11th International IBPSA Conference. 2009: Glasgow, Scotland (UK). p. 944-951.

36. Tokura, M., T. Iwata, and M. Shukuya, Experimental study on discomfort glare caused by windows; Development of a method for evaluating discomfort glare from a large light source. Journal of Architecture, Planning and Environmental Engineering, 1996. 489: p. 17-25.

37. Hopkinson, R.G., Glare from daylighting in buildings. Applied Ergonomics, 1972. 3(4): p. $206-215$.

38. Reinhart, C. and O. Walkenhorst, Validation of dynamic RADIANCE-based daylight simulations for a test office with external blinds. Energy and Buildings, 2001. 33(7): p. 683-697. 
39. Isoardi, G., V.R. Garcia-Hansen, and M. Hirning, Evaluation of the luminous environment in open-plan offices with skylights, in World Renewable Energy Forum (WREF) 2012, S. Greene, A. Sayigh, and C. Kutscher, Editors. 2012, Curran Associates, Inc.: Denver, Colorado (USA). p. 1-8.

40. Van Den Wymelenberg, K., M.N. Inanici, and P. Johnson, The Effect of Luminance Distribution Patterns on Occupant Preference in a Daylit Office Environment. Leukos, 2010. 7(2): p. 103-122.

41. Lee, E.S. and A. Tavil, Energy and visual comfort performance of electrochromic windows with overhangs. Building and Environment, 2007. 42(6): p. 2439-2449.

42. Asdrubali, F., Daylighting performance of sawtooth roofs of industrial buildings. Lighting Research \& Technology, 2003. 35(4): p. 343-359.

43. Juslén, H. and A. Tenner, Mechanisms involved in enhancing human performance by changing the lighting in the industrial workplace. International Journal of Industrial Ergonomics, 2005. 35(9): p. 843-855.

44. Konis, K., E.S. Lee, and R.D. Clear, Visual Comfort Analysis of Innovative Interior and Exterior Shading Systems for Commercial Buildings using High Resolution Luminance Images. Leukos, 2011. 7(3): p. 167-188.

45. Lee, E.S. and D.L. Di Bartolomeo, Application issues for large-area electrochromic windows in commercial buildings. Solar Energy Materials and Solar Cells, 2002. 71(4): p. 465-491.

46. Jakubiec, J.A. and C.F. Reinhart, Predicting visual comfort conditions in a large daylit space based on long-term occupant evaluations: a field study, in 13th Conference of International Building Performance Simulation Association. 2013: Chambéry, France.

47. Conraud, J., A methodology for the optimization of building energy, thermal, and visual performance. 2008, Concordia University: Montreal, Canada.

48. Dascalaki, E.G., et al., Indoor environmental quality in Hellenic hospital operating rooms. Energy and Buildings, 2009. 41(5): p. 551-560.

49. Alzubaidi, S. and P.K. Soori, Energy Efficient Lighting System Design for Hospitals Diagnostic and Treatment Room - A Case Study. Journal of Light \& Visual Environment, 2012. 36(1): p. 23-31.

50. Choi, J.H., L.O. Beltran, and H.S. Kim, Impacts of indoor daylight environments on patient average length of stay (ALOS) in a healthcare facility. Building and Environment, 2012. 50: p. 65-65.

51. Greenup, P., J.M. Bell, and I. Moore, The importance of interior daylight distribution in buildings on overall energy performance. 2001. 22(1-3): p. 45-52.

52. CEN, Light and lighting - Lighting of work places. Indoor work places. 2011, European Committee for Standardization: Brussels (BE).

53. Petherbridge, P. and R.G. Hopkinson, Discomfort glare and the lighting of buildings. Transactions of the Illuminating Engineering Society, 1950. 15: p. 29 - 79.

54. Walsh, J.W.T., The early years of illuminating engineering in Great Britain. Transactions of the Illuminating Engineering Society, 1951. 15(3): p. 49-60.

55. Guth, S.K., A method for the evaluation of discomfort glare. Illuminating Engineering, 1963. 57: p. $351-364$.

56. Judd, D.B., A flattery index for artificial illuminants. Illuminating Engineering, 1967. 62: p. 593-598.

57. Thornton, W.A., Color-Discrimination Index. Journal of the Optical Society of America, 1972. 62(2): p. 191-194.

58. Thornton, W.A., A validation of the color preference index. Journal of the Illuminating Engineering Society, 1974. 4: p. 48-52.

59. DIN 5035, Innenraumbeleuchtung mit künstlichem licht. 1979, Deutsches Institut für Normung.

60. Einhorn, H.D., Discomfort glare: a formula to bridge differences. Lighting Research and Technology, 1979. 11: p. 90-94.

61. Chauvel, P., et al., Glare from windows: current views of the problem. Lighting Research and Technology, 1982. 14(1): p. 31-46. 
62. Xu, H., Color-rendering capacity of illumination. Journal of the Optical Society of America, 1983. 73(12): p. 17091713.

63. Pointer, M.R., Measuring colour rendering-A new approach. Lighting Research and Technology, 1986. 18(4): p. 175-184.

64. CIE 17.4, International Lighting Vocabulary. 1987, Commission Internationale de l’Eclairage: Vienna, Austria.

65. Meyer, J.J., et al., Visual discomfort: Evaluation after introducing modulated light equipment, in Right Light, 2nd European Conference on Energy-Efficient Lighting. 1993: Arnhem (NL). p. 348-357.

66. CIE 17, Discomfort glare in interior lighting. 1995, Commission Internationale de l'Eclairage: Vienna, Austria.

67. Hashimoto, K., T. Yano, and Y. Nayatani, Proposal of practical method for calculating and indexing feeling of contrast for a light source. Illuminating Engineering Institute of Japan, 2000. 84: p. 843-849.

68. CIE 146/147, CIE Collection on Glare: CIE 146:2002 CIE Equations for Disability Glare and CIE 147:2002 Glare from Small, Large and Complex Sources. 2002, Commission Internationale de l'Eclairage: Vienna (AT).

69. Wienold, J. and J. Christoffersen, Towards a new daylight glare rating, in Lux Europa 2005 - 10th European Lighting Conference. 2005: Berlin (DE). p. 157-161.

70. Rogers, Z. and D. Goldman, Daylighting Metric Development Using Daylight Autonomy Calculations in the Sensor Placement Optimization Tool - Development Report and Case Studies 2006, Boulder, Colorado (USA). 52.

71. Davis, W. and Y. Ohno, Color quality scale. Optical Engineering, 2010. 49(3): p. 033602-033602-16.

72. Sicurella, F., G. Evola, and E. Wurtz, A statistical approach for the evaluation of thermal and visual comfort in freerunning buildings. Energy and Buildings, 2012. 47: p. 402-410.

73. IES, Approved Method: IES Spatial Daylight Autonomy (sDA) and Annual Sunlight Exposure (ASE). 2012, Illuminating Engineering Society.

74. Clear, R.D., Discomfort glare: What do we actually know? Lighting Research and Technology, 2013. 45(2): p. 141158.

75. Guo, X. and K.W. Houser, A review of colour rendering indices and their application to commercial light sources. Lighting Research \& Technology, 2004. 36(3): p. 183-199.

76. Rubiho, M., et al., Discomfort glare indices: a comparative study. Applied Optics, 1994. 33(34): p. 8001-8008.

77. EN 12464-1, Light and lighting - Lighting of work places. Indoor work places. 2011, European Committee for Standardization: Brussels, Belgium.

78. Tzempelikos, A. and A. Athienitis, The impact of shading design and control on building cooling and lighting demand. Solar Energy, 2007. 81(3): p. 369-382.

79. Lee, E. and S. Selkowitz, The New York Times headquarters daylighting mockup: Monitored performance of the daylighting control system. Energy and Buildings, 2006. 38(7): p. 914-929.

80. Chaiwiwatworakul, P., S. Chirarattananon, and P. Rakkwamsuk, Application of automated blind for daylighting in tropical region. Energy Conversion and Management, 2009. 50(12): p. 2927-2943.

81. Reinhart, C., Lightswitch-2002: a model for manual and automated control of electric lighting and blinds. Solar Energy, 2004. 77(1): p. 15-28.

82. David, M., et al., Assessment of the thermal and visual efficiency of solar shades. Building and Environment, 2011. 46(7): p. 1489-1496.

83. Moon, P. and D.E. Spencer, Illuminations from a non-uniform sky. Illuminating Engineering, 1942. 37: p. 707-726.

84. Mardaljevic, J., Rethinking daylighting and compliance, in SLL/CIBSE International Lighting Conference. 2013: Dublin (IE). p. 1-9.

85. CIBSE, Lighting Guide LG10 - Daylighting and windows design 1999, London: Chartered Institution of Building Services Engineers. 
86. BS 8206-2, Lighting for buildings - Part 2: Code of practice for daylighting in BS 8206-2, B.S. Institution, Editor. 2008: London UK.

87. Kota, S. and J. Haberl, Historical Survey of Daylighting Calculation Methods and Their use in Energy Performance Simulations, in 9th International Conference for Enhanced Building Operation. 2009: Austin, Texas (USA). p. 1-9.

88. ASE, Eclairage interieur par la lumicre du jour. 1989, Association Suisse Des Electriciens: Zurich (CH).

89. Olbina, S. and Y. Beliveau, Developing a transparent shading device as a daylighting system. Building Research and Information, 2009. 37(2): p. 148-163.

90. Slater, A.I. and P.R. Boyce, Illuminance uniformity on desks: Where is the limit? Lighting Research and Technology, 1990. 22(4): p. 165-174.

91. Dubois, M.C., Impact of Shading Devices on Daylight Quality in Offices - Simulations with Radiance, in Energy and Building Design. 2001, Lund University: Lund (SE). p. 1103-4467.

92. AS 1680, Code of Practice for Interior Lighting, S.A.o. Australia, Editor. 1976.

93. NSVV, Aanbevelingen voor binnenverlichting, N.S.v. Verlichtingskunde, Editor. 1981.

94. CIBSE, Code for interior lighting. 1984: Chartered Institution of Building Services Engineers.

95. BS 8206-1, Lighting for buildings - Part 1: Code of practice for artificial lighting, B.S. Institution, Editor. 1985: London, UK. p. 40.

96. CIE 29.2, Guide on Interior Lighting. 1986, Commission Internationale de l’Eclairage: Vienna, Austria.

97. Linney, A.S., Maximum Luminances and Luminance Ratios and their Impact on Users' Discomfort Glare Perception and Productivity in Daylit Offices. 2008, Victoria University of Wellington.: Wellington (NZ).

98. Jakubiec, A.J. and C.F. Reinhart, Diva 2.0: Integrating Daylight And Thermal Simulations Using Rhinoceros 3d, Daysim And Energyplus, in Building Simulation 2011 - 12th Conference of IBPSA. 2011: Sydney, (AU). p. 22022209.

99. Suk, J.Y., M. Schiler, and K. Kensek, Development of new daylight glare analysis methodology using absolute glare factor and relative glare factor. Energy and Buildings, 2013. 64: p. 113-122.

100. Shin, J., G. Yun, and J. Kim, View types and luminance effects on discomfort glare assessment from windows. Energy and Buildings, 2012. 46: p. 139-145.

101. Bülow-Hübe, H., Daylight in Glazed Office Buildings: A Comparative Study of Daylight Availability, Luminance and Illuminance Distribution for an Office Room with Three Different Glass Areas. 2008, Sweden: Lund University.

102. Osterhaus, W.K.E., Recommended Luminance Ratios and their Application in the Design of Daylighting Systems for Offices, in 35th Annual Conference of the Australia and New Zealand Architectural Science Association (ANZAScA). 2002: Geelong (AU).

103. Parpairi, K., et al., The Luminance Differences Index : A New Indicator of User Preferences in Daylit Spaces. Lighting Research and Technology, 2002. 34(1): p. 53-68.

104. Osterhaus, W.K.E., Design Guidelines for Glare-free Daylit Work Environments, in 11th European Conference on Lighting - Lux Europe. 2009: Istanbul (TR).

105. Fisekis, K., et al., Prediction of discomfort glare from windows. Lighting Research and Technology, 2003. 35: p. 360-371.

106. Boyce, P.R., Human Factors in Lighting. 2003, New York, Massachusetts (USA): Taylor \& Francis.

107. Iwata, T., et al., Discomfort caused by wide-source glare. Energy and Buildings, 1991. 15(3-4): p. 391-398.

108. IES, Outline of a Standard Procedure for Computing Visual Comfort Ratings for Interior Lighting. Journal of the Illuminating Engineering Society, 1973. 2(3): p. 328-344.

109. Luckiesh, M. and S.K. Guth, Brightness in visual field at borderline between comfort and discomfort (BCD). Journal of Illuminating Engineering Society, 1949. 44: p. 650-667. 
110. IES, Outline of a Standard Procedure for Computing Visual Comfort Ratings for Interior Lighting. Journal of the Illuminating Engineering Society, 1966. 61(10): p. 643-666.

111. Harrold, R., D. Mennie, and IESNA, IESNA Lighting Ready Reference: A Compendium of Materials from the IESNA Lighting Handbook 9th ed. Lighting Fundamentals. 2003: Illuminating Engineering Society of North America.

112. Cai, H. and T. Chung, Evaluating discomfort glare from non-uniform electric light sources. Lighting Research \& Technology, 2013. 45(3): p. 267-294.

113. Jakubiec, J. and C. Reinhart, The 'adaptive zone' - A concept for assessing discomfort glare throughout daylit spaces. Lighting Research \& Technology, 2012. 44(2): p. 149-170.

114. Waters, C., R. Mistrick, and C. Bernecker, Discomfort Glare from Sources of Non-uniform Luminance. Journal of the Illuminating Engineering Society, 1995. 24(2): p. 73-85.

115. Boubekri, M. and L. Boyer, Effect of window size and sunlight presence on glare. Lighting Research and Technology, 1992. 24(2): p. 69-74.

116. Iwata, T. and M. Tokura, Examination of the limitations of predicted glare sensation vote (PGSV) as a glare index for a large source: Towards a comprehensive development of discomfort glare evaluation. Lighting Research and Technology, 1998. 30(2): p. 81-88.

117. Meyer, J.J., D. Francioli, and P. Rey, Observed variations of lighting conditions versus feelings of visual discomfort in VDT operators: Application of a new model, in Lux Europa 1993. 1993: Edinburgh (UK). p. 332-339.

118. CIE 13.2, Method of measuring and specifying colour rendering properties of light sources. 1974, Commission Internationale de l'Eclairage: Paris, France.

119. van Trigt, C., Color rendering, a reassessment. Color Research \& Application, 1999. 24(3): p. 197-206.

120. Xu, H., Color-rendering capacity of illumination. Journal of the Illuminating Engineering Society, 1984. 12(2): p. 270-276.

121. Xu, H., Colour rendering capacity and luminous efficiency of a spectrum. Lighting Research \& Technology, 1993. 25: p. 131-132.

122. Pointer, M.R., Measuring Colour Rendering - A New Approach II. 2004, National Physical Laboratory: Teddington, UK.

123. CIE 177, Colour Rendering of White LED Light Sources. 2007, Commission Internationale de l'Eclairage: Vienna, Austria.

124. CIE. Technical Committees 23/01/2014]; $2014 \quad$ Available from: http://www.cie.co.at/index.php/Technical+Committees.

125. Houser, K.W., et al., Review of measures for light-source color rendition and considerations for a two-measure system for characterizing color rendition. Optics Express, 2013. 21(8): p. 10393-10411.

126. Nickerson, D. and C.W. Jerome, Color rendering of light sources: CIE method of specification and its application. Illuminating Engineering, 1965. 60(4): p. 262-271.

127. CIE 13.3, Method of measuring and Specifying Colour Rendering Properties of Light Sources. 1995, Commission Internationale de l'Eclairage: Vienna, Austria.

128. CIE/IEC, International Lighting Vocabulary, in CIE/IEC 17.4 1987, International Commission on Illumination and International Electrotechnical Commission.

129. US-DoE, LED Color Characteristics, in Solid-state lighting technology fact sheet. 2012, U.S. Department of Energy.

130. Philips, Basics of light and lighting, Philips, Editor. 2013.

131. Halonen, L., E. Tetri, and P. Bhusal, Chapter 5: Lighting technologies, in Guidebook on energy efficient electric lighting for buildings, L. Halonen, E. Tetri, and P. Bhusal, Editors. 2010, Aalto University School of Science and Technology: Aalto, Finland. p. 93-134.

132. Davis, W. and Y. Ohno, Approaches to color rendering measurement. Journal of Modern Optics, 2009. 56(13): p. 1412-1419. 
133. Sanders, C.L., Color preferences for natural objects. Illuminating Engineering, 1959. 54: p. $452-456$.

134. Smet, K., et al., Correlation between color quality metric predictions and visual appreciation of light sources. Optics Express, 2011. 19(9): p. 8151-8166.

135. Bartleson, C.J., Memory colors of familiar objects. Journal of the Optical Society of America, 1960. 50: p. $73-77$.

136. Buck, G.B. and H.C. Froelich, Color Characteristics of Human Complexions. Illuminating Engineering, 1948. 43: p. 27-49.

137. Hashimoto, K. and Y. Nayatani, Visual clarity and feeling of contrast. Color Research \& Application, 1994. 19(3): p. 171-185.

138. Hashimoto, K., et al., New method for specifying color-rendering properties of light sources based on feeling of contrast. Color Research \& Application, 2007. 32(5): p. 361-371.

139. Rea, M.S. and J.P. Freyssinier-Nova, Color rendering: A tale of two metrics. Color Research \& Application, 2008. 33(3): p. 192-202. 